\title{
Molecular Mechanisms in Perirhinal Cortex Selectively Necessary for Discrimination of Overlapping Memories, but Independent of Memory Persistence
}

\author{
Magdalena Miranda, ${ }^{1}$ Brianne A. Kent, ${ }^{3}$ (D) Juan Facundo Morici, ${ }^{2}$ (D)Francisco Gallo, ${ }^{1,2}$ Noelia V. \\ Weisstaub, ${ }^{2}{ }^{-}$Lisa M. Saksida, ${ }^{4,5,6}$ - Timothy J. Bussey, ${ }^{4,5,6}$ and ${ }^{-1}$ Pedro Bekinschtein ${ }^{1}$
}

\section{DOI:http://dx.doi.org/10.1523/ENEURO.0293-17.2017}

${ }^{1}$ Laboratory of Memory Research and Molecular Cognition, Institute for Cell Biology and Neuroscience CONICET and University of Buenos Aires Medical School, Buenos Aires, Argentina, ${ }^{2}$ Systems Neuroscience Group, Laboratory of Experimental Cognition and Behavior, Institute of Physiology and Biophysics, IFIBIO "Houssay," CONICET and University of Buenos Aires Medical School, Buenos Aires, Argentina, ${ }^{3}$ Department of Medicine, University of British Columbia, Vancouver, BC, Canada, ${ }^{4}$ Department of Psychology and MRC/Wellcome Trust Behavioural and Clinical Neuroscience Institute, University of Cambridge, Cambridge, UK, ${ }^{5}$ Molecular Medicine Research Group, Robarts Research Institute, and Department of Physiology and Pharmacology, Schulich School of Medicine and Dentistry, Western University, London, ON, Canada, and ${ }^{6}$ The Brain and Mind Institute, Western University, London, ON, Canada

\begin{abstract}
Successful memory involves not only remembering over time but also keeping memories distinct. The ability to separate similar experiences into distinct memories is a main feature of episodic memory. Discrimination of overlapping representations has been investigated in the dentate gyrus of the hippocampus (DG), but little is known about this process in other regions such as the perirhinal cortex (Prh). We found in male rats that perirhinal brain-derived neurotrophic factor (BDNF) is required for separable storage of overlapping, but not distinct, object representations, which is identical to its role in the DG for spatial representations. Also, activity-regulated cytoskeletal-associated protein (Arc) is required for disambiguation of object memories, as measured by infusion of antisense oligonucleotides. This is the first time Arc has been implicated in the discrimination of objects with overlapping features. Although molecular mechanisms for object memory have been shown previously in Prh, these have been dependent on delay, suggesting a role specifically in memory duration. BDNF and Arc involvement were independent of delay-the same demand for memory persistence was present in all conditions-but only when discrimination of similar objects was required were these mechanisms recruited and necessary. Finally, we show that BDNF and Arc participate in the same pathway during consolidation of overlapping object memories. We provide novel evidence regarding the proteins involved in disambiguation of
\end{abstract}

\section{Significance Statement}

In this article, we show, outside of the hippocampus, the molecular mechanisms underlying the ability to separate similar experiences into distinct memory representations (thought to result from the computational mechanism of pattern separation). The dentate gyrus (DG) is thought to disambiguate representations belonging to any domain, but other regions could also perform this operation. Although molecular mechanisms have been shown previously in the perirhinal cortex (Prh), these have always been dependent on delay, suggesting a role specifically in memory persistence. We report that, despite the profound anatomic differences between the perirhinal cortex (Prh) and the DG, the discrimination of overlapping memories in these regions relies on the same molecular mechanisms. 
object memories outside the DG and suggest that, despite the anatomical differences, similar mechanisms underlie this process in the DG and Prh that are engaged depending on the similarity of the stimuli.

Key words: Arc; BDNF; object recognition; pattern separation; perirhinal cortex

\section{Introduction}

Two similar stimuli could be associated with two very different experiences: a cat inside your house may be friendly, whereas a puma could be threatening to your life. It is thought that the brain creates unique representations of similar events, which are less confusable and can be associated with different outcomes, through a process called pattern separation (Treves and Rolls, 1994; Gilbert et al. 1998; Leutgeb et al. 2007). The original computational models define the process in terms of a transformation of input representations into output representations that are less correlated with each other (Marr, 1971; Treves and Rolls, 1994; McClelland et al. 1995). Thus, pattern separation increases the likelihood of accurate encoding and subsequent retrieval. It has been studied effectively using electrophysiology (Leutgeb et al. 2007; Neunuebel and Knierim, 2014), and we and others have developed tasks to demonstrate the relevance of pattern separation processes to cognition (Gilbert et al. 1998; Kirwan and Stark, 2007; Clelland et al. 2009; Toner et al. 2009; Creer et al. 2010; Bekinschtein et al. 2013).

Because episodic memory involves the recollection of unique events, separation of similar experiences is proposed to be an essential component for the storage of nonconfusable representations of these episodes and has been studied mainly in the hippocampus (Ranganath, 2010). Indeed, the computational models focus specifically on DG granule cells, which are thought to be a

Received August 21, 2017; accepted September 11, 2017; First published October 12, 2017

The authors declare no competing financial interests.

Author contributions: M.M., N.V.W., L.M.S., T.J.B., and P.B. designed research; M.M., B.K., J.F.M., F.G., and P.B. performed research; M.M., N.V.W., and P.B. analyzed data; L.M.S., T.J.B., and P.B. wrote the paper.

This work was funded by the Biotechnology and Biological Sciences Research Council (grant BB/G019002/1) to TJB, LMS, and PB; the National Agency for Promotion of Science and Technology (PICT 2012-1119) to PB; the IBRO Return Home Fellowship to PB; and the ISN Return Home Award to PB.

Magdalena Miranda's present address is Instituto De Neurociencia Cognitiva y Traslacional, Universidad Favaloro, Instituto De Neurología Cognitiva y CONICET, Buenos Aires, Argentina; Juan Facundo Morici's present address is Instituto De Neurociencia Cognitiva y Traslacional, Universidad Favaloro, Instituto De Neurología Cognitiva y CONICET, Buenos Aires, Argentina; Francisco Gallo's present address is Instituto De Neurociencia Cognitiva y Traslacional, Universidad Favaloro, Instituto De Neurología Cognitiva y CONICET, Buenos Aires, Argentina; Noelia V. Weisstaub's present address is Instituto De Neurociencia Cognitiva y Traslacional, Universidad Favaloro, Instituto De Neurología Cognitiva y CONICET, Buenos Aires, Argentina; Pedro Bekinschtein's present address is Instituto De Neurociencia Cognitiva y Traslacional, Universidad Favaloro, Instituto De Neurología Cognitiva y CONICET, Buenos Aires, Argentina.

Correspondence should be addressed to Pedro Bekinschtein, Solís 453, 6th floor, Buenos Aires (C1078AAl), Argentina. E-mail: pbekinschtein@fmed.uba.ar or pebekins@gmail.com.

DOI:http://dx.doi.org/10.1523/ENEURO.0293-17.2017

Copyright (C) 2017 Miranda et al.

This is an open-access article distributed under the terms of the Creative Commons Attribution 4.0 International license, which permits unrestricted use, distribution and reproduction in any medium provided that the original work is properly attributed. domain-general pattern separator (Yassa and Stark, 2011), well suited for performing pattern separation on overlapping inputs from the entorhinal cortex. Adult neurogenesis in the $D G$ has been shown to be required for discrimination of overlapping representations in the spatial domain (Gilbert et al. 1998; Clelland et al. 2009; Bekinschtein et al. 2014a), and some studies have begun to elucidate the molecular basis involved in this process (Bekinschtein et al. 2013, 2014b).

Because the hippocampus is known to mediate spatial memory in rodents, with the exception of a few studies (e.g., Johnson et al. 2017), most tasks used to evaluate the behavioral outputs thought to result from discrimination of overlapping representations in rodents have involved some kind of contextual or spatial manipulation (Gilbert et al. 1998; Clelland et al. 2009; Kheirbek et al. 2012; Nakashiba et al. 2012; Bekinschtein et al. 2013). However, this type of disambiguation could, in principle, occur during encoding of representations other than spatial, for example for objects in Prh (Kent et al. 2016). Indeed, disambiguation of object representations has been shown to require Prh (Bussey et al. 2002; Bartko et al. 2007), and it has been proposed that Prh discriminates similar objects by storing unique conjunctive representations of these items (Bussey et al. 2002; Bartko et al. 2007). However, it has been suggested that the DG is a domain-general discriminator of both spatial and object representations, among other types. Although molecular mechanisms have been shown previously in Prh, these have always been dependent on delay, suggesting a role specifically in persistence (Winters and Bussey, 2005b; Seoane et al. 2012). Manipulation of the Prh during acquisition or after learning produced delay-dependent effects on memory, but this does not indicate a specific effect on the ability to disambiguate similar input stimuli. It is not known whether a putative function of Prh in object disambiguation operates via the same molecular mechanisms as those shown within the DG (Bekinschtein et al. 2013).

In this work, we tested whether Prh is involved in the consolidation of overlapping object memories through plasticity-related mechanisms such as brain-derived neurotrophic factor (BDNF) that have been implicated during discrimination of overlapping spatial memories. We found that BDNF, a protein essential for memory storage (Bekinschtein et al. 2014a), is required for disambiguation of memories for similar objects in Prh, just as it is for spatial memories in the hippocampus. In addition, we found that activity-regulated cytoskeletal-associated protein (Arc), a molecule important for plasticity and memory (Bramham et al. 2010), is also required. This immediate early gene product has emerged as a key protein in memory formation and different types of synaptic plasticity, including long-term potentiation (LTP), long-term depression (LTD), and homoeostatic synaptic scaling (Bramham et al. 2010). Arc is strongly associated with neuronal activity related to 
behaviorally relevant experiences (Guzowski et al. 2005). In addition, this molecule has been shown to be required in various structures for different types of learning such as fear conditioning (Ploski et al. 2008) and inhibitory avoidance (Martínez et al. 2012). Arc-deficient mice present deficits in several learning tasks such as water-maze fear conditioning, conditioned taste aversion, and novel object recognition (Plath et al. 2006). This evidence points at Arc as a possible target of BDNF action. Finally we demonstrated that BDNF is likely to act upstream of Arc during the consolidation of "pattern-separated" object memories. We suggest that discrimination of similar, but not distinct, stimuli in the medial temporal lobe occurs not only in the DG, but also in the Prh, depending on the nature of the representations. Importantly, similar mechanisms underlie the discrimination of overlapping memories wherever it occurs, and these mechanisms are different from those that vary with demand on memory persistence.

\section{Materials and Methods}

\section{Subjects}

The subjects were 201 male Long-Evans rats from our breeding colony, weighing $\sim 250-300 \mathrm{~g}$ at the start of testing. The rats were housed on a reversed 12-h light/ 12-h dark cycle (lights on 1900-0700), in groups of two or four. All behavioral testing was conducted during the dark phase of the cycle. Rats were food deprived to $85 \%-90 \%$ of their free feeding weight to increase spontaneous exploration, except during recovery from surgery, where food was available ad libitum. Water remained available ad libitum throughout the study. All experimentation was conducted in accordance with the National Animal Care and Use Committee of the University of Buenos Aires (CICUAL) and strict compliance with the guidelines of the University of Cambridge and United Kingdom Animals (Scientific Procedures) Act 1986 and the Amendment Regulations 2012.

\section{Surgery and cannulation}

All rats were implanted bilaterally in Prh with 22-gauge indwelling guide cannulas. Subjects were anaesthetized with ketamine (Holliday; $74 \mathrm{mg} / \mathrm{kg}$, i.p.) and xylazine (Konig; $7.4 \mathrm{mg} / \mathrm{kg}$, i.p.) and placed in a stereotaxic frame (David Kopf Instruments) with the incisor bar set at -3.2 $\mathrm{mm}$. Guide cannulas were implanted according to the following coordinates, measured relative to the skull at bregma (Paxinos and Watson, 1998): anteroposterior $-5.5 \mathrm{~mm}$, lateral $\pm 6.6 \mathrm{~mm}$, dorsoventral $-7.1 \mathrm{~mm}$. The cannulas were secured to the skull using dental acrylic and three jeweler screws. Obturators, cut to sit flush with the tip of the guide cannulas and with an outer diameter of $0.36 \mathrm{~mm}$, were inserted into the guides and remained there except during infusions. At the completion of each surgery, an antibiotic was applied for $3 \mathrm{~d}$ (enrofloxacin; $0.27 \mathrm{mg} / \mathrm{kg}$, Vetanco). Animals were given at least 7 days to recover before drug infusions and behavioral testing.

\section{Infusion procedure}

Depending on the experiment, rats received bilateral infusions of oligonucleotides (ODNs, $4 \mathrm{nmol} / \mu \mathrm{l} / 0.5 \mu \mathrm{l}$ side; Genbiotech), human recombinant BDNF $(0.5 \mu \mathrm{g} / \mu \mathrm{l} /$ $0.5 \mu \mathrm{l}$ side; Byoscience), emetine $(50 \mu \mathrm{g} / \mu \mathrm{l} / 0.5 \mu \mathrm{l}$ side; Sigma-Aldrich), or saline at different times during the behavioral task. The injection volume was always $0.5 \mu \mathrm{l} /$ side. ODNs were HPLC-purified phosphorothioate endcapped 18-mer sequences, dissolved in sterile saline to a concentration of $4 \mathrm{nmol} / \mu \mathrm{l}$. All ODNs were phosphorothioated on the three terminal bases of both $5^{\prime}$ and $3^{\prime}$ ends. This modification results in increased stability and less toxicity of the ODN. Sequences are as follows: BDNF-ASO, 5' -TCTTCCCCTTTTAATGGT-3'; BDNFMSO, 5'-ATACTTTCTGTTCTTGCC-3'; Arc-ASO, 5' GTCCAGCTCCATCTGCTCGC-3'; Arc-MSO, 5' CGTGCACCTCTCGCAGCTTC-3'. All ODN sequences were subjected to a BLAST search on the National Center for Biotechnology Information BLAST server using the GenBank database. Control MSO sequence, which included the same 18 nucleotides as the ASO but in a scrambled order, did not generate any full matches to identified gene sequences in the database. Bilateral infusions were conducted simultaneously using two 5- $\mu$ l Hamilton syringes that were connected to the infusion cannulas by propylene tubing. Syringes were driven by a Harvard Apparatus precision syringe pump, which delivered $0.5 \mu \mathrm{l}$ to each hemisphere over $2 \mathrm{~min}$. The infusion cannulas were left in place for an additional minute to allow for diffusion. At least $3 \mathrm{~d}$ were allowed for washout between repeated infusions.

\section{Immunoblot assays}

After rats were killed, brains were immediately frozen and the Prh was microdissected. Tissue was homogenized in ice-chilled buffer (20 mM Tris-HCl [pH 7.4], 0.32 M sucrose, 1 mM EDTA, 1 mM EGTA, 1 mM PMSF, 10 $\mathrm{mg} / \mathrm{ml}$ aprotinin, $15 \mathrm{mg} / \mathrm{ml}$ leupeptin, $10 \mathrm{mg} / \mathrm{ml}$ bacitracin, $10 \mathrm{mg} / \mathrm{ml}$ pepstatin, $15 \mathrm{mg} / \mathrm{ml}$ trypsin inhibitor, $50 \mathrm{mM}$ $\mathrm{NaF}$, and $1 \mathrm{mM}$ sodium orthovanadate). Samples of homogenates (15 $\mu \mathrm{g}$ of protein) were subjected to $10 \%$ or $12 \%$ SDS-PAGE under reducing conditions. Proteins were transferred onto nitrocellulose membranes (Bio-Rad) in transfer buffer $(25 \mathrm{mM}$ Tris, $192 \mathrm{mM}$ glycine, $10 \%$ $\mathrm{vol} / \mathrm{vol}$ methanol) for $2 \mathrm{~h}$ at $100 \mathrm{~V}$. Western blots were performed by incubating membranes first with anti-BDNF antibody (N20, 1:1000, Santa Cruz Biotechnology), with anti-Arc antibody (1:2000, Santa Cruz Biotechnology) and anti-actin antibody (1:5000, Santa Cruz Biotechnology). One nanogram of recombinant human BDNF was used as a standard for Western blot (rhBDNF, Alomone). Blots were developed using enhanced chemiluminescence (GE Healthcare), visualized by Storm 845 Phosphorlmager (GE Healthcare Life Sciences), and quantified using ImageJ software $(\mathrm{NIH})$. For analysis, optical density (OD) values and the band areas were obtained for each microdissected hippocampal sample for both the target protein (BDNF, Arc) and the actin loading control. Each target OD value was normalized to its corresponding actin OD value, and normalized levels were averaged for each condition. 
A
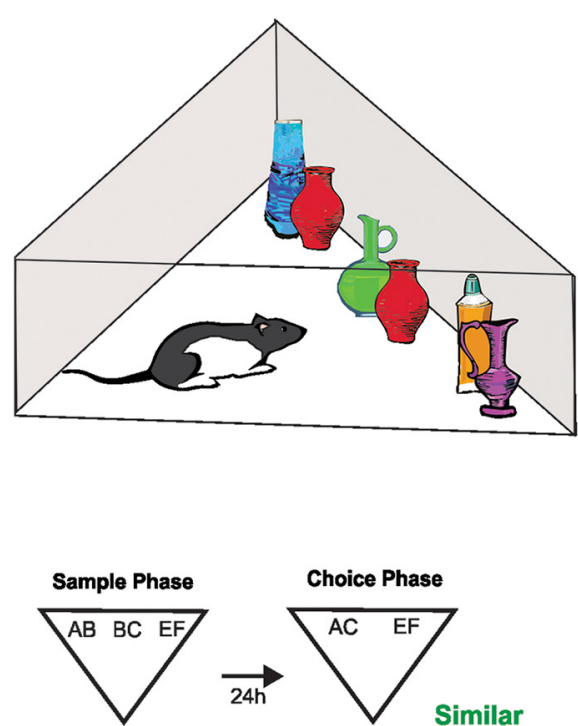

Similar
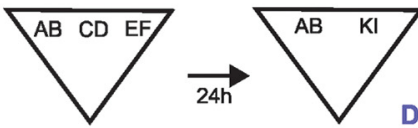

Dissimilar
B

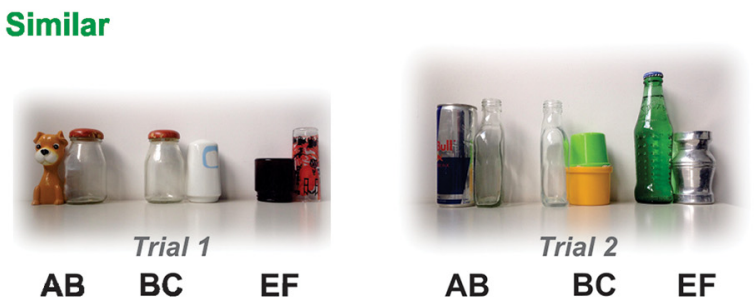

Dissimilar
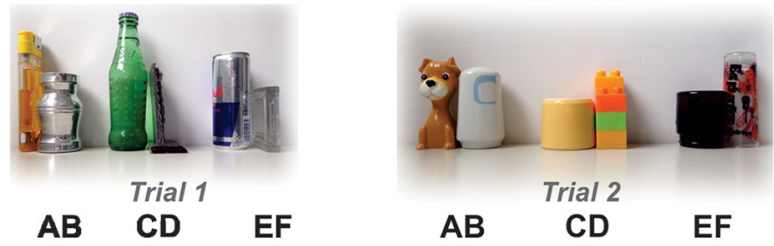

Extra-similar

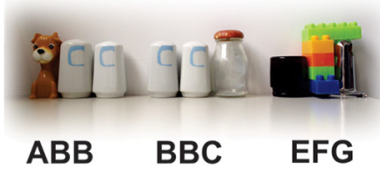

Figure 1. $\boldsymbol{A}$, Left, cartoon depicting the apparatus and the spontaneous object recognition task (SOR). $\boldsymbol{B}$, Representative objects for trials 1 and 2 for the similar and dissimilar versions of the SOR task and the extra-similar version of the SOR task.

Data were analyzed using a one-way ANOVA followed by Newman-Keuls post hoc comparisons. Data depicted in Fig. 2D were transformed before analysis.

\section{Apparatus}

The triangular open field used for the spontaneous object recognition task (SOR) was made of white foam board. Each wall was $60 \mathrm{~cm}$ long by $60 \mathrm{~cm}$ high. The circular open field (90 cm diameter, $45 \mathrm{~cm}$ high) used for the spontaneous location recognition task (SLR) was made of black plastic. Both open fields were situated in the middle of a dimly lit room. The walls of the triangular open field were higher to minimize the visual access to the distal cues in the room. The circular open field was surrounded by four spatial cues and standard furniture. The open field floor was always covered with wood shavings. A video camera was positioned over the arena, and sample and choice phases were recorded for later analysis. The objects for the SOR task were made of two different smaller objects, except for the extra-similar condition, in which they were made by three smaller objects. Composite objects were made by simply attaching together two or three of the smaller items in the conditions described in Results (Fig. 1). We always used different objects for our within-subject design (examples can be seen in Fig. 1). For the SLR, the objects used were either soda cans or beer bottles from which the label had been removed. All objects were fixed to the floor of the open field with Blu-tack and cleaned with a $50 \%$ ethanol solution between sample and choice trials. For the SOR task, all three composite objects were aligned close to one of the walls of the arena, and positions within this line were pseudorandomly assigned. Other tasks that evaluate object discrimination have used objects built with LEGO. While LEGO-constructed objects offer some versatility when trying to manipulate the similarity between them, they could also cause more interference, as the texture would be the same between the different objects made of the same material. In fact, it has been shown that merely the fact that an object is built with LEGO can cause interference with another LEGO object that is not particularly similar (Bartko et al. 2010). Junk object features offer different textures and curvy shapes that are not present in LEGO-based objects.

For the SLR task (Fig. 5D,E), positions varied according to the condition tested, with objects always placed along a circumference $15 \mathrm{~cm}$ away from the wall and $30 \mathrm{~cm}$ away from the center of the arena. For the similar condition, objects were separated by a $50^{\circ}$ angle; and for the dissimilar condition, they separated by an angle of $120^{\circ}$.

\section{Behavioral procedures}

For the SOR task (Fig. 1), each rat was handled for $3 \mathrm{~d}$ and then habituated to the arena for $5 \mathrm{~min} / \mathrm{d}$ for $3 \mathrm{~d}$ before exposure to the objects (Figs. 2, 3, 5, 6, and 8). For the SLR task (Fig. 5D,E), each rat was handled for $3 \mathrm{~d}$ and then habituated to the arena for $10 \mathrm{~min} / \mathrm{d}$ for $5 \mathrm{~d}$ before exposure to the objects. For the SOR task, after habituation, the rats were exposed during a 5-min duration sample phase to three objects made of either two or three features depending on the condition. For the similar condition, two of the objects shared one feature (AB and $B C$ ) 
A

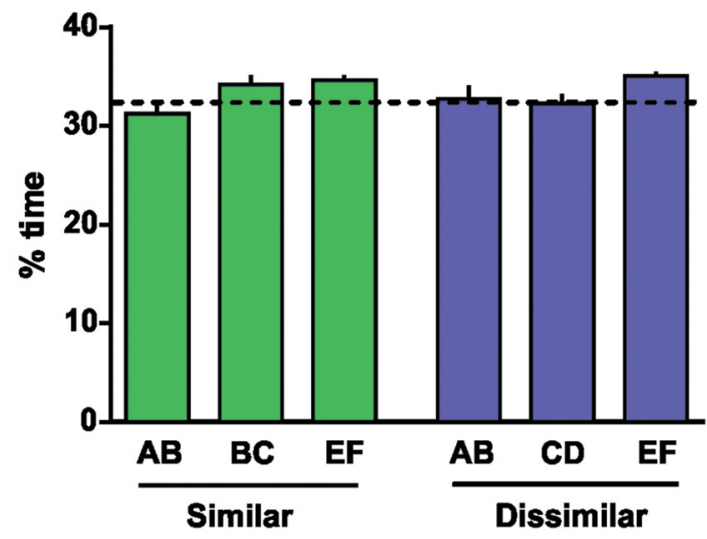

B

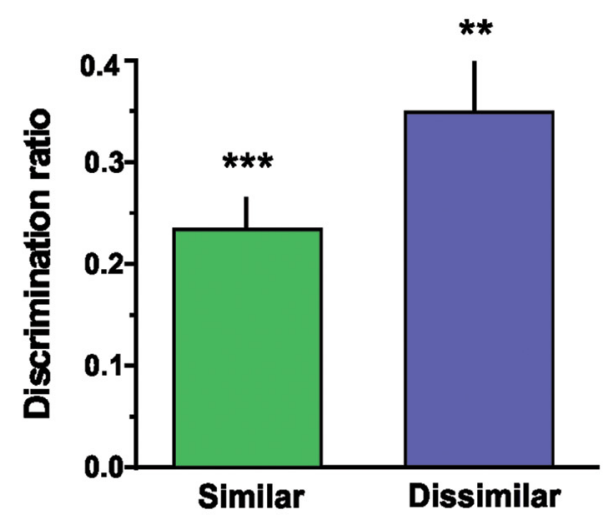

C
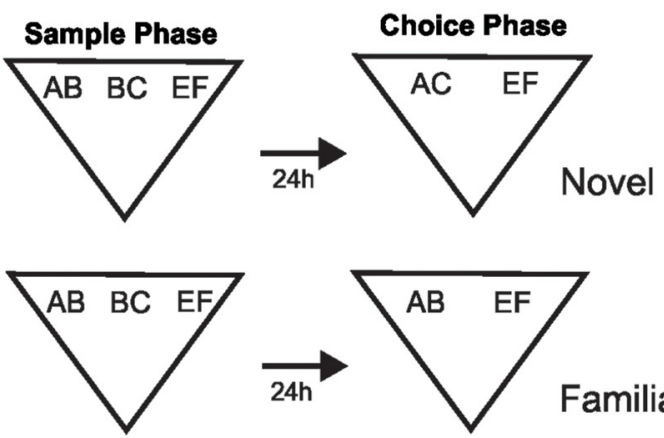

Familiar

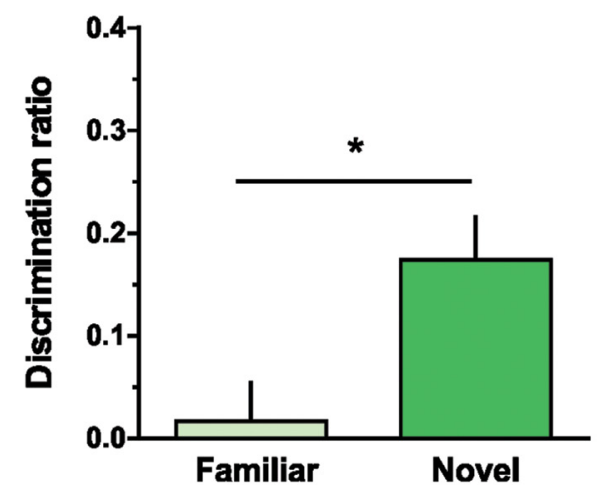

Figure 2. The spontaneous object recognition task. $\boldsymbol{A}$, Percentage of time spent exploring each of the objects in the sample phase in the dissimilar (left) and similar (right) condition. Rats spent an equal amount of time exploring each of the three objects during the sample phase. Similar: repeated-measures one-way ANOVA (\%time), $F_{\text {obj }}=2.829, p=0.125, F_{\text {ind }}=1.624 \times 10^{-13}, p>0.999$; dissimilar: repeated-measures one-way ANOVA (\%time), $F_{\text {obj }}=1.456, p=0.274, F_{\text {ind }}=1.014 \times 10^{-13}, p>0.999$. B , Discrimination ratios during the choice phase, $24 \mathrm{~h}$ after the sample phase, in the similar and dissimilar condition. One-sample $t$ test (similar, $t=$ 8.11), $p<0.0001$; one sample $t$ test (dissimilar, $t=4.361), p=0.003$; similar versus dissimilar paired $t$ test $(t=1.521), p=0.172$, $n=8$. $\boldsymbol{C}$, Left, control task. Right, discrimination ratios during the choice phase for the novel and familiar conditions. Paired $t$ test $(t=2.861), p=0.0187, n=10, d=0.054$. Data are expressed as the mean $\pm \mathrm{SEM} ; *, p<0.05 ; * *, p<0.01 ; * * *, p<0.001$.

and the third object was made of two other different features (EF). For the dissimilar condition, all three objects were made of different features (AB, CD, and EF). For the extra-similar condition (Fig. $8 A-D$ ), two of the objects shared two of three features (ABB and $\mathrm{BBC}$ ), and the third one was different (EFG). The choice phase lasted $3 \mathrm{~min}$ and was conducted $24 \mathrm{~h}$ after the finalization of the sample phase. In this case, the animals were exposed to two objects, one novel and one familiar, that varied in composition according to the condition evaluated. For the similar condition, the novel object was made of the two nonshared features of the objects presented in the sample phase (AC), and the familiar object was a copy of the third object (EF). For the dissimilar condition, the novel object was made of two novel features $(\mathrm{GH})$, and the familiar object was a copy of one of the objects presented during the sample phase (AB, $C D$, or $E F)$. Because most of the experiments involved a within-subject design, the letters do not indicate that we used the same object or feature. We always used different objects and features for the different trials. The rationale behind the task was that if the rats were able to separate the two similar objects, their representations should be distinct and resistant to confusion; therefore, the rats should show preference for the novel object during the retrieval phase. However, if the representations of the two similar objects were not sufficiently separated, presentation of the new object would activate a familiar representation in memory and would thus not be distinguishable. The result would be that rats should behave as if the new object was familiar. As this process is thought to happen during encoding/consolidation stages of memory formation, the similarity of the to-be-remembered objects was varied during encoding/ consolidation, rather than the retrieval phase of the task. Unlike other tests of discrimination (Gilbert et al. 1998; Clelland et al. 2009; Nakashiba et al. 2012), the use of a continuous variable as a measure of performance yields sufficient data within a single trial to allow manipulations at different stages of memory. In contrast, previous tasks using discrete trial procedures required many trials to 
A

BDNF ASO/MSO

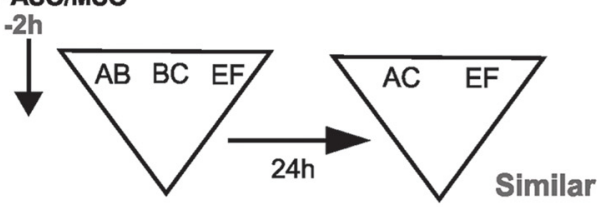

BDNF ASO/MSO

B

S-SOR
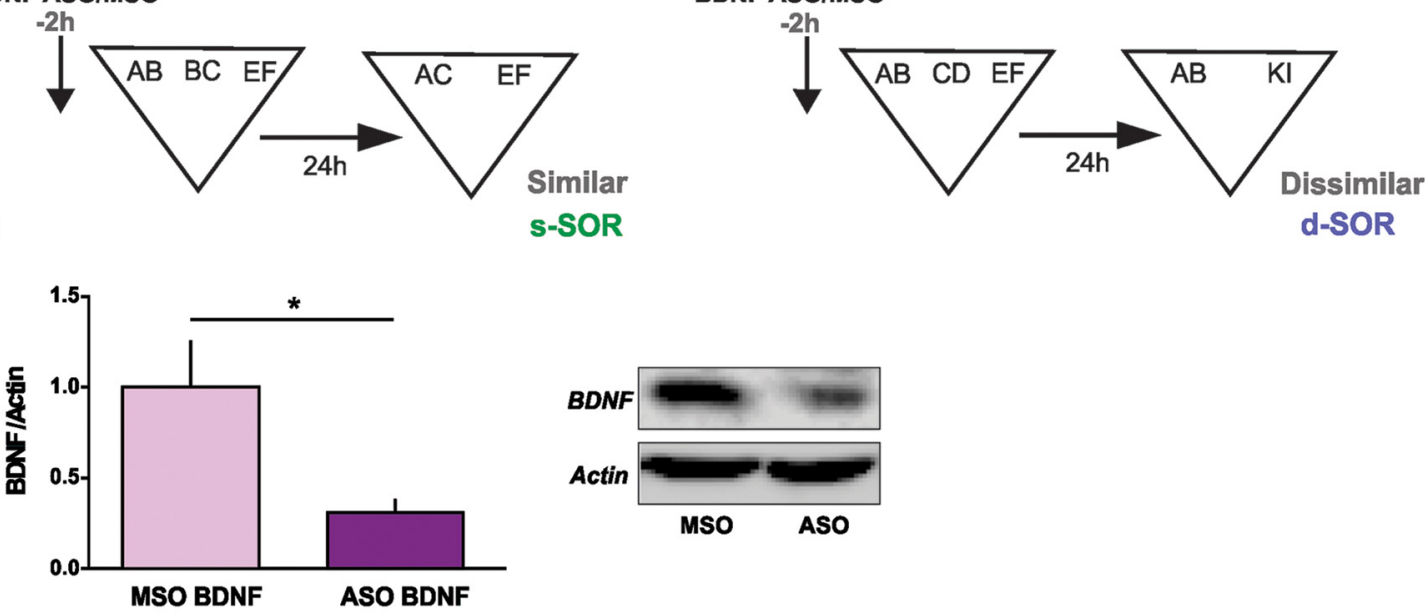

C

S-SOR
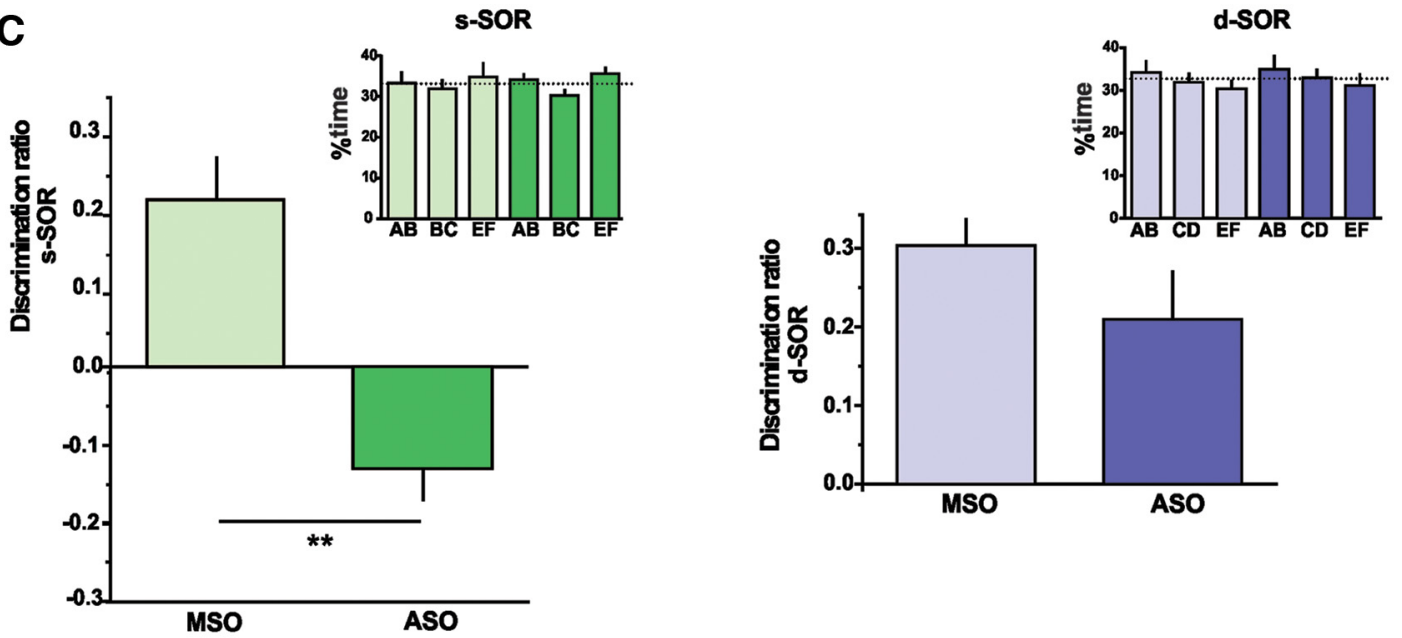

D
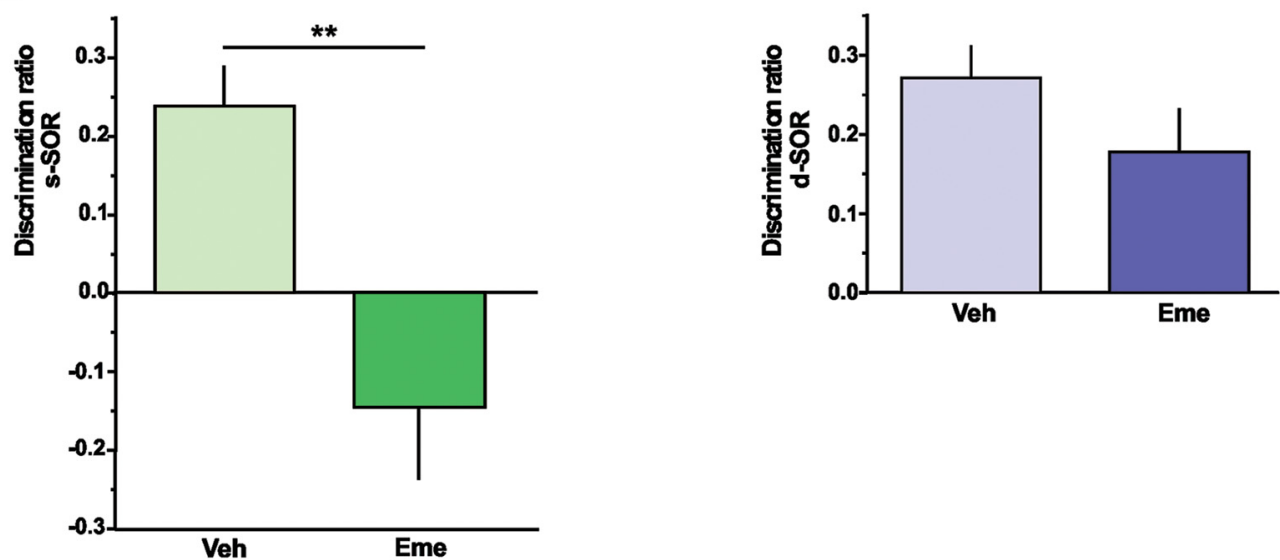

Figure 3. BDNF expression and protein synthesis in the Prh are required for consolidation of similar, but not dissimilar, object memory representations. A, Schematic illustration of the two configurations of the SOR task depicting the time point at which BDNF-ASO was infused. $\boldsymbol{B}$, BDNF protein levels in the Prh of nontrained animals infused with either BDNF-ASO or BDNF-MSO $2 \mathrm{~h}$ before injection of kainic acid into the Prh. Unpaired $t$ test $(t=2.334), p=0.0322, n=9-10, d=0.377$. $\boldsymbol{C}$, Effect of BDNF-ASO or BDNF-MSO injections on the discrimination ratios for the similar (s-SOR) and the dissimilar (d-SOR) version of the task. Paired $t$ test $(t=4.284)$, $p=0.0036, n=8-13, d=2.284$. Inset, percentage of time spent exploring each of the objects in the sample phase in the s-SOR (left) and d-SOR (right), $2 \mathrm{~h}$ after BDNF-MSO (light color) or BDNF-MSO (dark color). Similar: repeated-measures two-way ANOVA; 
continued

$F=0.652, p($ drug $)=0.440, F=0.957, p$ (object) $=0.403, F=0.135, p$ (interaction) $=0.875$. Dissimilar: repeated-measures two-way ANOVA; $F=0.055, p$ (drug) $=0.818, F=1.388, p$ (object) $=0.269, F=0.001, p$ (interaction) $=0.999$. $D$, The injection of emetine in the $\mathrm{PRH} 15 \mathrm{~min}$ before the sample phase impaired performance on the s-SOR task during the choice phase $24 \mathrm{~h}$ later relative to vehicle-injected rats (left), whereas there was no effect of emetine on the $\mathrm{d}$-SOR version of the task (right). Paired $t$ test (s-SOR, $t=$ 3.540), $p=0.0076, n=9, d=1.698$; paired $t$ test (d-SOR, $t=1.284), p=0.231, n=10$. Data are expressed as the mean \pm SEM; $*, p<0.05 ; * *, p<0.01$.

collect sufficient data, and thus such manipulations would have to be repeated an impracticable number of times.

For the extra-similar condition (Fig. $8 A-D$ ), the novel object was made of a novel combination of familiar features (ABC), and the familiar object was a copy of the third object presented in the sample phase (EFG). Exploration was recorded and later scored manually for both the sample and choice phases. For all experiments, exploration of a particular object was defined as the rat having its nose directed at the object at a distance of $2 \mathrm{~cm}$ or less, or touching the object with its nose. Rearing with the head oriented upward did not count as exploration. Climbing over or sitting on the objects was not included. Two people scored the videos; one was blind to the novel and familiar objects. There was no significant interrater variability.

For the SLR task (Fig. 5D,E), after habituation, rats were exposed to three identical objects, $A 1, A 2$, and $A 3$, during a sample phase that lasted for $10 \mathrm{~min}$. For the similar SLR (s-SLR), objects A2 and A3 were placed $50^{\circ}$ apart (20.5 $\mathrm{cm}$ between them) and object $\mathrm{A} 3$ at an equal distance from the other two. For the dissimilar SLR (D-SLR), objects $A 1, A 2$, and $A 3$ were equidistant, $120^{\circ}(49 \mathrm{~cm}$ between them) apart from each other. Twenty-four hours after the sample phase, rats were exposed to two new identical copies of the objects, A4 and A5, for $5 \mathrm{~min}$. New identical copies were used to prevent the use of olfactory cues. During this choice phase, object A4 was placed in a familiar location (same position as in the sample phase) and object $A 5$ was placed in a novel location. For the s-SLR task, the novel location was defined as a position exactly in between the ones in which objects A2 and A3 were located during the sample phase (see schemes in Fig. 5D). For the D-SLR task, object A4 was placed in a familiar location and object $A 5$ in a position equidistant to the previous locations of A2 and A3 (see schemes in Fig. $5 D)$.

\section{Experimental design and statistical analysis}

For all the experiments, the results were expressed as a discrimination ratio that was calculated as the time exploring the novel object (SOR) or the object in the novel location (SLR) minus the time exploring the familiar object (SOR) or the object in the familiar location (SLR) divided by total exploration time $\left[\left(t_{\text {novel }}-t_{\text {familiar }}\right) / t_{\text {total }}\right]$. In Fig. $2 C$, one-sample $t$ test was used to compare the discrimination ratio from the similar and dissimilar conditions to verify that the ratio was different from zero. For the experiment shown in Fig. $2 \mathrm{C}$, half of the rats were tested first in the "novel condition" and then in the "familiar condition," and the other half were tested first for the familiar and then for the novel conditions. Discrimination ratios were com- pared within subject using a paired $t$ test. For experiments shown in Figs. $3 C, D, 4 C, 5 A, E$, and $6 B$, rats were tested twice. In the first trial, half of the animals received ASO injection and the other half received MSO injection. In the second trial, they were injected with either ASO or MSO depending on what they had received in the first trial. For the sample phase, the percentage of time exploring each object was compared using a repeated-measures twoway ANOVA, with time and object as the repeated measures. For the choice phase, discrimination ratios were compared within subject using a paired $t$ test. Different features $(A, B, C$, etc.) were used to reproduce the same task conditions in the consecutive trials of the withinsubject design. For the experiment in Fig. $8 F$, animals were tested twice, once injected with Arc-ASO and BDNF-ASO in the hemisphere and once with Arc-ASO and BDNF-ASO in different hemispheres. Control MSO was injected in the other hemisphere. Discrimination ratios were compared within subject using a paired $t$ test. For the experiments shown in Fig. 8B,D, animals were tested only once, and discrimination ratios were analyzed using a $t$ test, or a two-way ANOVA followed by Bonferroni post hoc comparisons. In all experiments, drug and vehicle or ASO and MSO injections were counterbalanced. We performed one-sample $t$ tests for every discrimination ratio to analyze whether control animals learned the task.

\section{Histology}

At the completion of behavioral testing, all rats except the ones used for additional experiments were anaesthetized by i.p. injection with $2 \mathrm{ml}$ of Euthatal (Rhône Merieux) and perfused transcardially with PBS, followed by $10 \%$ neutral buffered formalin. The brains were removed and postfixed in formalin for at least $24 \mathrm{~h}$ before being immersed in $20 \%$ sucrose solution until they sank. Sixtymicrometer sections were cut on a freezing microtome encompassing the extent of the injector track. Every fifth section was mounted on a gelatin-coated glass slide and stained with cresyl violet. Slides were examined under a light microscope to verify the location of the injections. For analysis of ODN spread after injection, rats were injected with $2 \mathrm{nmol} / \mu \mathrm{l}(0.5 \mu \mathrm{l} / \mathrm{side})$ of biotinylated ArcASO ODN, and $2 \mathrm{~h}$ later, they were anesthetized and perfused transcardially with $0.9 \%$ saline followed by $4 \%$ paraformaldehyde. The brains were isolated and sliced, and the ASO was detected by avidin-biotin staining (Bekinschtein et al. 2007)

\section{Results}

In the original SOR task (Ennaceur and Delacour, 1988; Warburton et al. 2000), rats are exposed during a sample 
A

Arc ASO/MSO

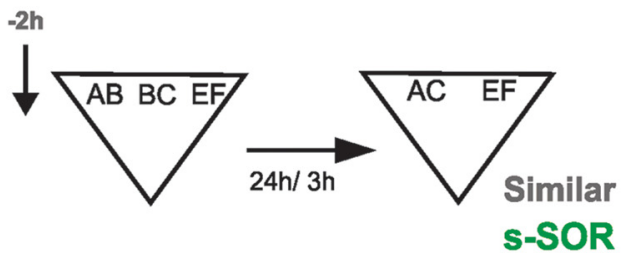

B

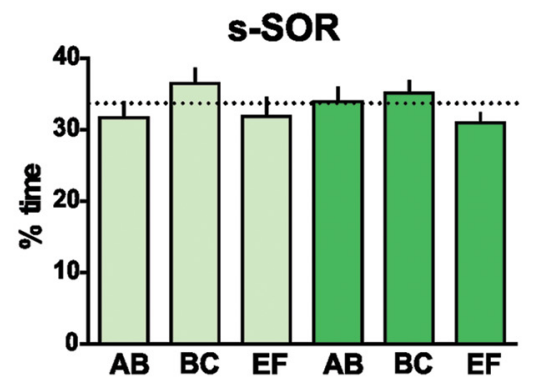

C

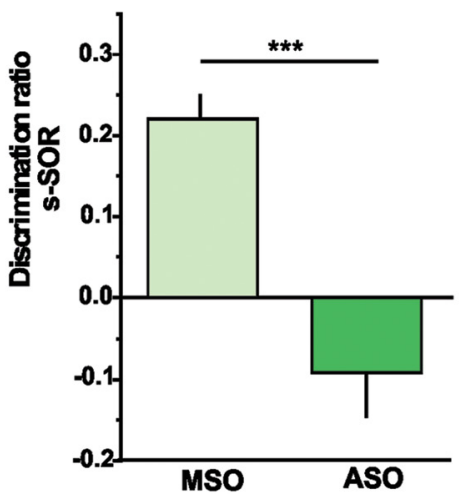

Arc ASO/MSO
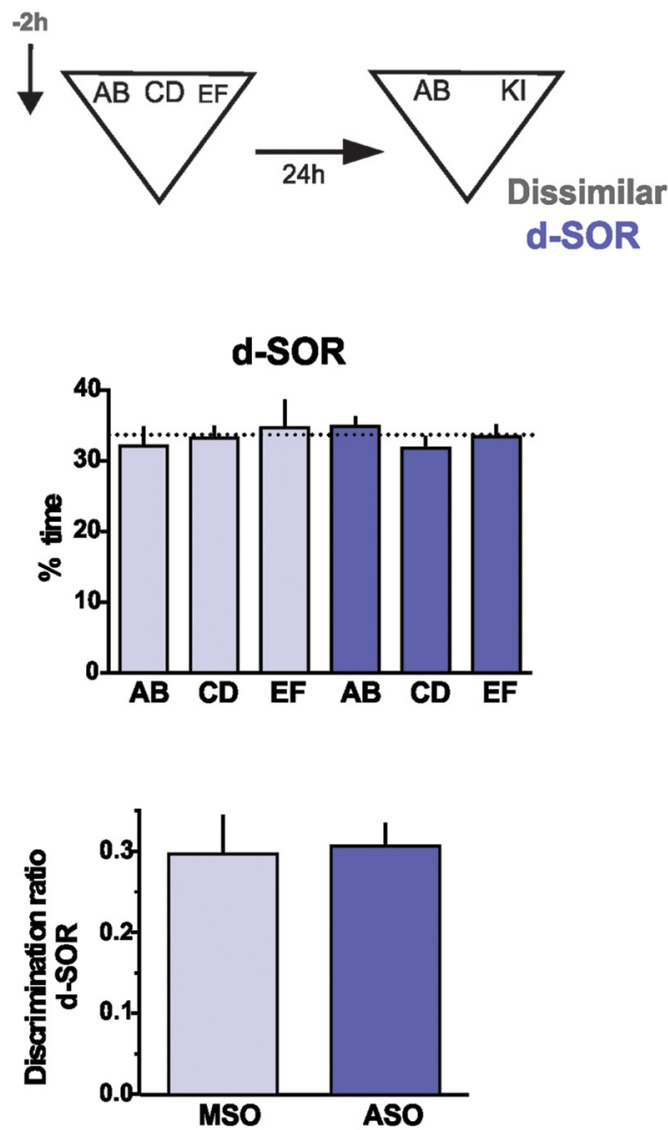

Figure 4. A, Arc expression in the Prh is required for consolidation of similar, but not dissimilar, object memory representations. $\boldsymbol{B}$, Percentage of time spent exploring each of the objects in the sample phase, $2 \mathrm{~h}$ after MSO (light color) or ASO (dark color) of Arc injection. Similar: repeated-measures two-way ANOVA; $F=0.026, p$ (drug) $=0.875, F=1.561, p$ (object) $=0.240, F=0.256$, $p$ (interaction) $=0.777$. Dissimilar: repeated-measures two-way ANOVA; $F=4615, p$ (drug) $=0.522, F=0.1971, p$ (object) $=0.824$, $F=0.2516, p$ (interaction) $=0.782$. (C) Effect of presample injection of Arc-ASO or Arc-MSO into the Prh in the choice phase at 24 $\mathrm{h}$ in the s-SOR (left) or the d-SOR (right) version of the task. Paired $t$ test (s-SOR, $t=5.762$ ), $p=0.0002, n=11, d=7599 ;$ paired $t$ test (d-SOR, $t=0.421), p=0.683, n=11$. Data are expressed as the mean \pm SEM; $* * *, p<0.001$.

phase to two identical objects placed within an arena. After a variable delay, rats are given a choice phase in which one of the objects is replaced by a completely novel object. Because rats naturally prefer novelty, rats with intact memory spend significantly more time exploring the novel object than the familiar one (Warburton et al. 2000). A detailed description of the modified task we used in this study can be found in Methods. Briefly, it consisted of a sample (study) phase in which rats are exposed to three objects, two of them similar to each other ( $A B$ and $B C$ ) and the third object dissimilar (EF; Fig. 1). This task is analogous to our SLR, which was developed as a test for spatial discrimination of overlapping memories (Bekinschtein et al. 2013). In SLR, the similarity between the spatial representations was manipulated by varying the distance between identical objects. In the analogous task used in the present study to evaluate discrimination of overlapping object memories during consolidation, the similarity between objects was manipulated by varying the number of features shared by them at the encoding phase (Fig. 1).

\section{Object exploration and preference is driven by novelty in the modified SOR task}

There were no differences in the percentage of time the animals spent exploring the three objects during the sample phase for the similar or the dissimilar conditions (Fig. $2 A$ ). In addition, the total amount of time rats spent exploring did not differ between conditions (similar versus dissimilar: paired $t$ test, $p=0.943$ ). The choice phase or test was conducted $24 \mathrm{~h}$ after the sample phase, and 
A

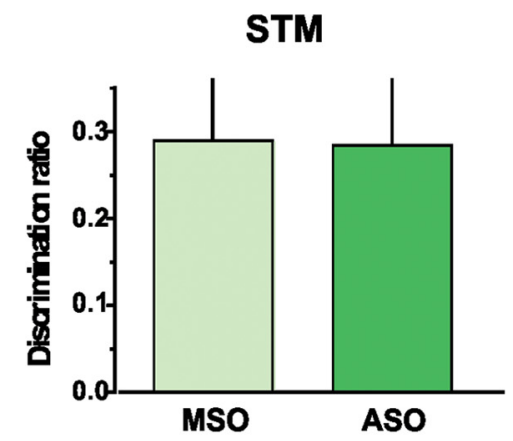

B
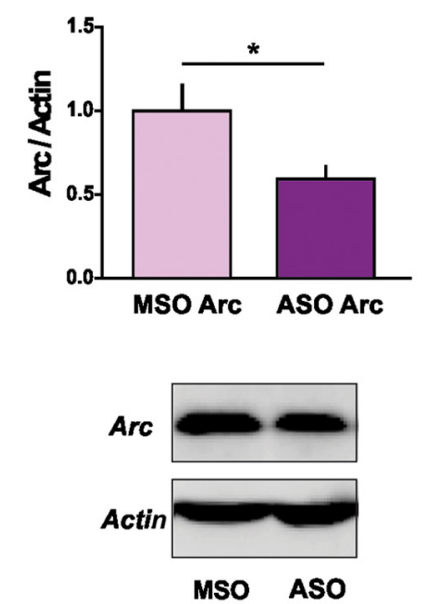

C
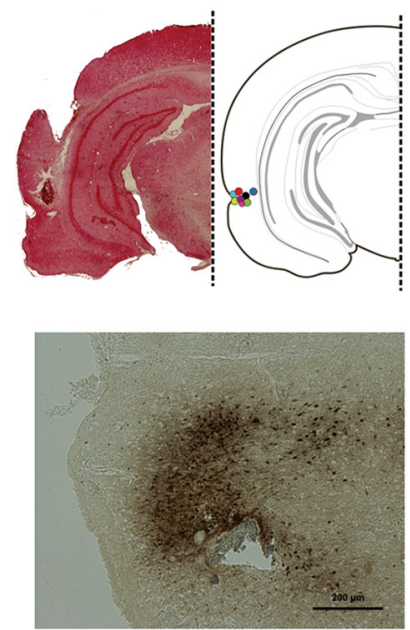

D
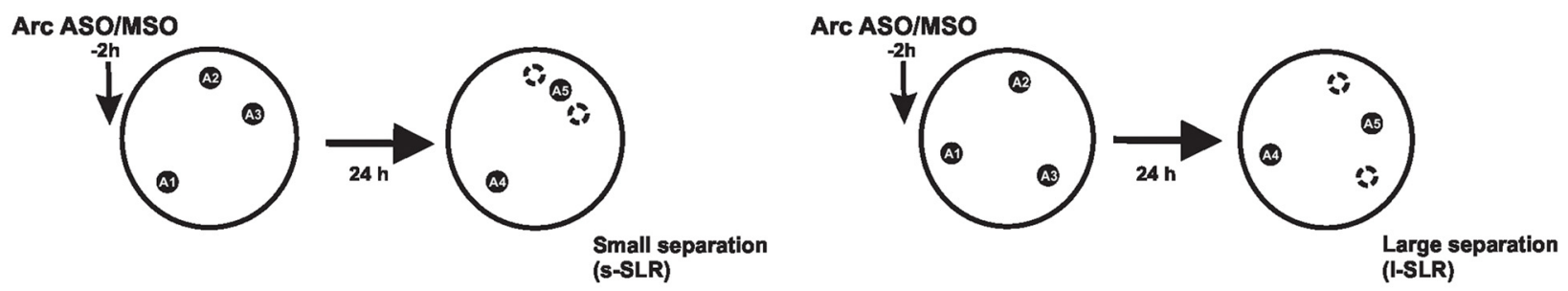

E
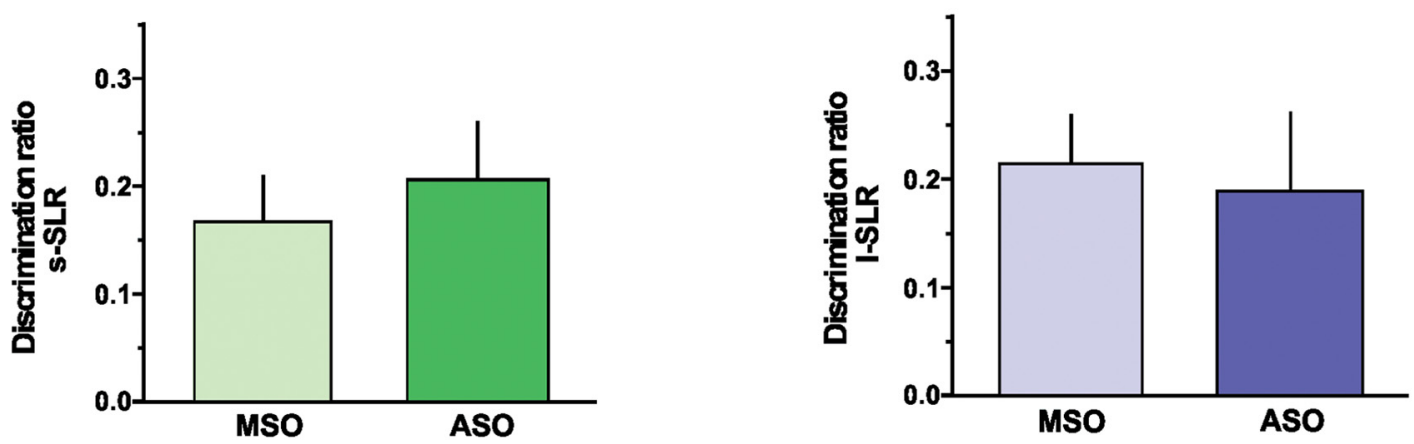

Figure 5. Arc expression in the Prh is not necessary for discrimination of overlapping spatial representations or for short-term memory. A, Short-term memory test after the injection of Arc-ASO or MSO $2 \mathrm{~h}$ previous to the s-SOR. Paired $t$ test $p=0.974, t=$ $0.0343, n=6$. Data are expressed as the mean \pm SEM. $\boldsymbol{B}$. Arc protein levels in the Prh of nontrained animals infused with either Arc-ASO or MSO $2 \mathrm{~h}$ before injection of kainic acid into the Prh. Unpaired $t$ test $p=0.046, t=2.317, n=5-6, d=1.644$. C, Upper panel, coronal section showing the track of the cannula and indicating representative infusion sites in the Prh. Lower panel, representative spread of a biotinylated Arc-ASO in the Prh $2 \mathrm{~h}$ after injection of $2 \mathrm{nmol}$. $\boldsymbol{D}$, Schematic representation of the similar configuration (s-SLR, left) and dissimilar configuration of the spontaneous location recognition task (L-SLR, right) showing the time of infusion of Arc-ASO or MSO. E, Effect of Arc-ASO or Arc-MSO infusion into Prh in the SLR task. Paired $t$ test (s-SLR, $t=0.521$ ), $p=0.618$; paired $t$ test (D-SLR, $t=0.713), p=0.499, n=8$. Data expressed as the mean $\pm \mathrm{SEM} ; *, p<0.05$.

memory was evaluated by comparing the amount of time spent exploring a novel object and a familiar object. In the similar condition, the novel object was made of the nonoverlapping (AC) features of the two similar objects from the sample phase ( $A B$ and $B C)$, and the familiar object was a copy of the third one presented in the sample phase (EF; Fig. 1). Rats spent significantly more time exploring the novel than the familiar object (Fig. $2 B$, Table 3 ), indi- cating that they were able to store separate representations of the similar objects presented during the sample phase and to recognize the new object as novel despite it being made of familiar features. A similar result was obtained for the dissimilar condition in which a novel object made of two completely new features $(K L)$ was paired against a familiar object seen during the sample phase (AB, CD, or EF; Fig. 2B). 
A

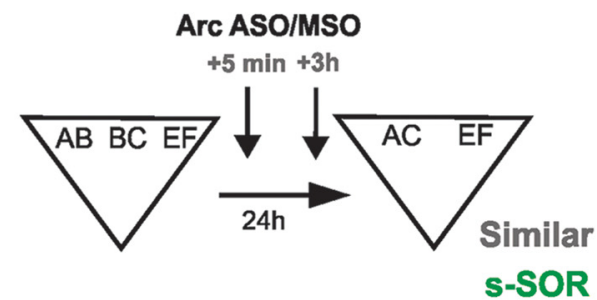

B
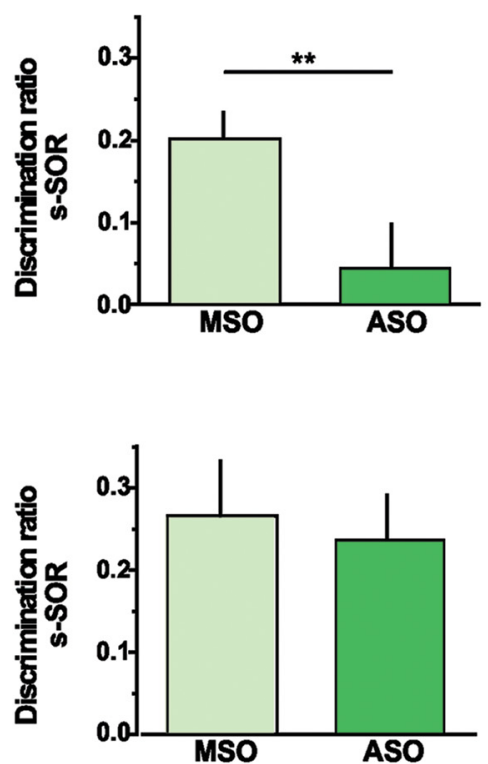

Arc ASO/MSO

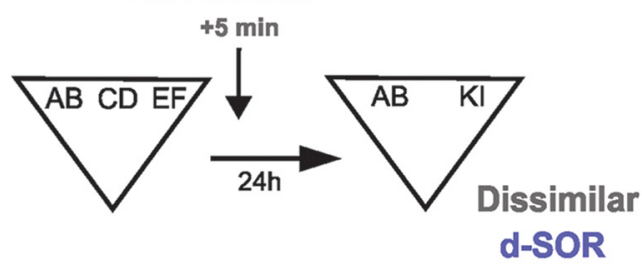

d-SOR

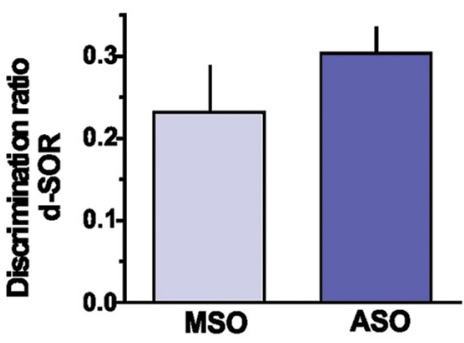

$+5 \mathrm{~min}$

$+3 h$

Figure 6. Arc expression in the Prh is required in a time-restricted window for consolidation of similar object memory representations. $\boldsymbol{A}$, Schematic illustration of the similar (s-SOR, left) or dissimilar (d-SOR right) task configurations depicting the time points at which Arc-MSO or ASO was infused. B, Effect of the injection of Arc-ASO or Arc-MSO into the Prh 5 min or $3 \mathrm{~h}$ after the sample phase in the s-SOR (left) or the d-SOR (right) version of the task evaluated in a choice phase $24 \mathrm{~h}$ later. Paired $t$ test (similar $0 \mathrm{~h}, t=2.274$ ), $p=0.046, n=11, d=1.611$; paired $t$ test (dissimilar $0 \mathrm{~h}, t=0.999), p=0.351, n=8$; paired $t$ test $(\operatorname{similar} 3 \mathrm{~h}, t=0.459), p=0.663$, $n=7$. Data are expressed as the mean \pm SEM; $* *, p<0.01$.

These results indicate that intact animals were able to spontaneously disambiguate the representations of two similar objects seen $24 \mathrm{~h}$ before the test. However, there was a possibility that the rats explored the novel object more during the choice phase due to a change in the number of items from three to two between the sample and the choice phases. To rule out that the difference in the novelty coming from the change in the number of objects was driving exploration preferentially to one of them, we presented two familiar objects during the choice phase and compared either AB or BC against EF (Fig. 2C). There was no preference for any of the two objects after this manipulation, indicating that item novelty was the main driver for exploration in this task (Fig. 2C, Table 3). Although in the novel condition, the discrimination ratio was different from zero, this was not the case for the familiar condition $\left(p_{\mathrm{fam}}=0.68, t=0.43 ; p_{\text {novel }}=0.016\right.$, $t=3.97$; one-sample $t$ test). Object location was always pseudorandomly assigned in case there was a bias for location within the arena.

\section{BDNF and protein synthesis are required for the discrimination of overlapping object representations in Prh}

Long-term storage of information in the brain is thought to require structural changes at the synapses (Kandel, 2001). Stable forms of synaptic plasticity and memory have long been known to depend on neuronal activity-induced protein synthesis (Davis and Squire, 1984; McGaugh, 2000). BDNF is a neurotrophin shown to be essential for memory consolidation in different learning tasks, including object recognition (Bekinschtein et al. 2014a). In addition, BDNF can induce long-term potentiation in the DG (Messaoudi et al. 2007). We have previously demonstrated that BDNF is required for consolidation of overlapping spatial memories in the DG (Bekinschtein et al. 2013); thus, we hypothesized that it may participate in this process in Prh as well.

To evaluate the requirement of BDNF in the SOR task, we injected an antisense oligonucleotide for BDNF (BDNF-ASO) or a missense control oligonucleotide with the same base composition but in a random order (BDNFMSO) in Prh $2 \mathrm{~h}$ before the sample phase for the similar 
Table 1. Total exploration times during the sample sessions for Figs. 2, 3, and 4

\begin{tabular}{|c|c|c|c|}
\hline $\begin{array}{l}\text { Figure } \\
2 A\end{array}$ & $A B$ & $\mathrm{BC} / \mathrm{CD}$ & EF \\
\hline s-SOR & $32.40 \pm 1.72$ & $37.75 \pm 2.98$ & $36.22 \pm 2.25$ \\
\hline d-SOR & $34.23 \pm 2.45$ & $33.79 \pm 2.12$ & $38.42 \pm 2.91$ \\
\hline \multicolumn{4}{|l|}{$3 C$} \\
\hline \multicolumn{4}{|l|}{ s-SOR } \\
\hline BDNF-MSO & $27.76 \pm 4.06$ & $27.59 \pm 4.00$ & $34.14 \pm 4.09$ \\
\hline $\begin{array}{l}\text { BDNF-ASO } \\
\text { d-SOR }\end{array}$ & $31.06 \pm 4.83$ & $27.54 \pm 5.30$ & $32.04 \pm 5.41$ \\
\hline BDNF-MSO & $26.07 \pm 3.06$ & $24.64 \pm 3.70$ & $23.26 \pm 3.77$ \\
\hline BDNF-ASO & $24.93 \pm 2.94$ & $27.75 \pm 3.72$ & $25.65 \pm 3.12$ \\
\hline \multicolumn{4}{|l|}{$3 D$} \\
\hline \multicolumn{4}{|l|}{ s-SOR } \\
\hline Vehicle & $31.82 \pm 2.99$ & $25.98 \pm 2.92$ & $28.81 \pm 3.27$ \\
\hline $\begin{array}{l}\text { Emetine } \\
\text { d-SOR }\end{array}$ & $30.86 \pm 5.35$ & $25.21 \pm 3.91$ & $29.84 \pm 4.10$ \\
\hline Vehicle & $32.58 \pm 3.70$ & $30.92 \pm 3.94$ & $31.38 \pm 3.28$ \\
\hline Emetine & $34.37 \pm 4.05$ & $31.98 \pm 5.09$ & $30.48 \pm 3.92$ \\
\hline \multicolumn{4}{|l|}{$\begin{array}{l}4 B \\
\text { s-SOR }\end{array}$} \\
\hline Arc-MSO & $36.06 \pm 3.07$ & $43.03 \pm 2.87$ & $38.44 \pm 3.54$ \\
\hline $\begin{array}{l}\text { Arc-ASO } \\
\text { d-SOR }\end{array}$ & $39.24 \pm 3.36$ & $39.27 \pm 3.82$ & $36.21 \pm 4.51$ \\
\hline Arc-MSO & $38.74 \pm 2.63$ & $38.19 \pm 1.66$ & $42.46 \pm 4.46$ \\
\hline Arc-ASO & $37.39 \pm 2.48$ & $33.49 \pm 2.81$ & $36.15 \pm 3.51$ \\
\hline
\end{tabular}

Results are expressed as mean \pm SEM in seconds.

and dissimilar versions of the SOR task (Fig. $3 A$ ). To first ensure that BDNF-ASO was efficiently blocking BDNF expression in Prh, we infused either ASO or MSO $2 \mathrm{~h}$ before injection of kainic acid or vehicle into the Prh of naive animals. This method was previously used to induce immediate-early genes (Nakayama et al. 2015). Thirty minutes after kainic acid injection, the Prh was dissected out and processed for Western blot analysis of BDNF protein content. BDNF-ASO, but not BDNF-MSO, was able to block the increase in BDNF expression caused by kainic acid (Fig. 3B), indicating that the ASO was effectively preventing BDNF expression. It is unlikely that BDNF-ASO reduced steady-state levels at the time of the sample phase. Previous experiments using fear learning have shown an amnesic effect on long-term memory of presample BDNF blocking antibodies, but not of BDNFASO, suggesting that BDNF-ASO acts only on de novo BDNF synthesis (Slipczuk et al. 2009). Although in this work we did not perform a dose-response curve of BDNF-ASO on BDNF protein levels, previous work showed that $2 \mathrm{~h}$ postinjection, there were no differences in BDNF steady-state levels between BDNF-ASO and BDNF-MSO in the dorsal hippocampus (Bekinschtein et al. 2007). This also suggests that in these experiments, BDNF-ASO blocks BDNF expression induced by learning. Animals in both groups explored the three objects equally (Fig. 3C, inset; Table 1). When the animals were evaluated $24 \mathrm{~h}$ later, we found a significant difference in the discrimination ratio between BDNF-ASO- and BDNF-MSO- injected animals only for the similar SOR (Fig. 3C), but no differences in total exploration times (see Table 5; paired $t$ test, $p_{\text {similar }}=0.945, p_{\text {dissimilar }}=0.523$,). One-sample $t$ test indicate that BDNF-MSO-injected animals did learn the s-SOR and d-SOR tasks $\left(p_{\text {similar }}=0.01, t=3.38\right.$; $\left.p_{\text {dissimilar }}<0.0001, t=8.55\right)$, whereas BDNF-ASO-injected animals learned only the d-SOR task $\left(p_{\text {similar }}=\right.$ $0.16, t=3.14 ; p_{\text {dissimilar }}=0.006, t=3.35$ ). We have seen negative discrimination ratios before, but see Discussion for an interpretation of this particular result. This indicates that BDNF is required for acquisition and/or consolidation of overlapping object memories in Prh.

If BDNF was specifically involved in consolidation, then infusion of the BDNF-ASO should not affect short-term memory. To evaluate this, we injected BDNF-ASO or MSO into Prh and tested short-term memory in the similar version of the task. We did not find a significant difference between ASO and MSO. Both ODNs were infused $2 \mathrm{~h}$ before the sample phase, and memory was evaluated $3 \mathrm{~h}$ postacquisition. We found that both groups remembered equally (BDNF-MSO DR $0.23 \pm 0.03$ versus BDNF-ASO DR $0.24 \pm 0.03, n=7, p=0.63, t_{6}=0.50$, paired $t$ test). We next asked whether specific expression of BDNF was involved in the process of consolidating overlapping memories and whether other molecules could participate in a process of storing nonoverlapping memories in Prh. If this were the case, contrary to the effects of BDNF blockade, general inhibition of protein synthesis in Prh should impair SOR both in the similar and the dissimilar condition. To block protein synthesis, we injected the translation inhibitor emetine (Sigma-Aldrich) into Prh, $15 \mathrm{~min}$ before the sample phase in both the similar and dissimilar conditions. When memory was evaluated $24 \mathrm{~h}$ later, we found a deficit for the emetine-injected group only in the similar condition (Fig. 3D, left). No memory impairment was observed in emetine-injected animals that were evaluated in the dissimilar condition (Fig. 3D, right). Onesample $t$ tests indicated that vehicle-injected animals were able to learn both the s-SOR and the d-SOR $\left(p_{\text {similar }}=\right.$ $0.001, t=4.75 ; p_{\text {dissimilar }}<0.0001, t=6.67$ ), whereas emetineinjected animals learned only the d-SOR version $\left(p_{\text {similar }}=0.16\right.$, $t=1.5 ; p_{\text {dissimilar }}=0.01, t=3.22$ ). These results suggest that protein synthesis in Prh is required for consolidation of overlapping, but not nonoverlapping, memories and that BDNF participates in a general protein synthesis-dependent mechanism of disambiguation of object memories in Prh.

\section{Arc/Arg3.1 expression is required for the discrimination of overlapping object memories in Prh}

We then decided to look for a potential effector of BDNF in Prh. Most studies have focused on the study of Arc in brain regions such as the hippocampus and amygdala, and there is no information regarding the role of Arc in object recognition in Prh or specifically in pattern separation. In addition, BDNF-induced long-term potentiation in the DG is dependent on Arc synthesis (Messaoudi et al. 2007). Thus we hypothesized that Arc expression could be induced by BDNF in Prh during consolidation of similar object memories.

We focused this set of experiments on the function of the Arc protein in Prh during storage and disambiguation of object representations. As with BDNF, the expression of Arc can be efficiently blocked by the application of antisense oligonucleotides (ASO) that bind specifically to 
the Arc mRNA (Messaoudi et al. 2007; Ploski et al. 2008; Martínez et al. 2012; Nakayama et al. 2015). We infused Arc-ASO or a control missense oligonucleotide (Arc-MSO) in Prh $2 \mathrm{~h}$ before the sample phase and tested the animals $24 \mathrm{~h}$ later. Infusion of the ODNs did not affect total exploration times during the sample phase (see Table 5; ASO versus MSO, paired $t$ test, $p_{\text {similar }}=0.585 ; p_{\text {dissimilar }}=$ 0.919 ), and rats spent an equal amount of time exploring each one of the three objects (Fig. 4B, Table 1). However, infusions of the ODNs impaired object recognition memory for the similar, but not for the dissimilar, condition (Fig. 4C). One-sample $t$ tests indicate that Arc-MSO-injected animals were able to learn both the s-SOR and the d-SOR $\left(p_{\text {similar }}<0.0001, t=7.14 ; p_{\text {dissimilar }}<0.0001, t=11.8\right)$, whereas Arc-ASO-injected animals learned only the d-SOR version $\left(p_{\text {similar }}=0.13, t=1.64 ; p_{\text {dissimilar }}<\right.$ $0.0001, t=10.8)$. No memory impairment was observed when Arc-ASO was infused $2 \mathrm{~h}$ before the sample phase and the animals were evaluated after $3 \mathrm{~h}$ (Fig. 5A). Onesample $t$ tests indicated that both Arc-MSO- and ArcASO-injected animals were able to remember the s-SOR task at $3 \mathrm{~h}\left(p_{\text {similarmso }}=0.04, t=2.8 ; p_{\text {similarAso }}=0.02\right.$, $t=3.3$ ). There were no differences in total exploration times between ASO- and MSO-injected animals during the choice phase (see Table 4; paired $t$ test, $p_{\text {similar }}=$ 0.206 ; $p_{\text {dissimilar }}=0.875$ ). This indicates that initial acquisition of the task was not affected by Arc blockade and that the effect of this manipulation was dependent on the delay between sample and choice, suggesting that the effect was happening during the consolidation phase. To ensure that Arc-ASO was efficiently blocking Arc expression in Prh, we infused either ASO or MSO $2 \mathrm{~h}$ before injection of kainic acid or vehicle into the Prh of naive animals. Thirty minutes after kainic acid injection, the Prh was dissected out and processed for Western blot analysis of Arc protein content. Arc-ASO, but not Arc-MSO, was able to block the increase in Arc expression caused by kainic acid (Fig. 5B), indicating that the ODN was effectively preventing Arc expression.

These results cannot be explained by unspecific damage to Prh by the oligonucleotide Arc-ASO, because no change in performance was seen after administering Arc$\mathrm{MSO}$, and staining did not reveal any lesion to the site of infusion (Fig. 5C). In addition, the experimental design was within-subject, so every rat was both injected with ASO and MSO. Thus, it is very unlikely that ASO and MSO had differential toxic effects that were somehow reversible. We evaluated ODN spread $2 \mathrm{~h}$ after injection of biotinylated Arc-ASO into Prh. We found little spread outside Prh, indicating that the observed deficit was not caused by blocking Arc expression in other structures (Fig. 5C).

\section{Arc expression in Prh is not necessary for DG- dependent discrimination of overlapping spatial representations}

Another interpretation of these results could be that Arc is required in Prh for discrimination of similar information of any kind or that the impairment is evident or not depending on the difficulty of the task. If this were the case, then disambiguation of similar information, regardless of the type of stimuli involved, should also be affected by injection of Arc-ASO into Prh. To evaluate this possibility, we tested the rats in a spontaneous spatial discrimination task that is particularly sensitive to manipulations of the DG (Bekinschtein et al. 2013, 2014b; Fig. 5D). As with our version of the SOR, the spontaneous location recognition task (SLR) can be run in two different conditions, the similar/small separation (s-SLR) and the dissimilar/large separation (I-SLR) configurations (Fig. 5D). Similarity of the locations can be manipulated by varying the distance between the objects within a circular arena surrounded by distal spatial cues. The s-SLR, but not the I-SLR is sensitive to DG manipulations like blockade of BDNF (Bekinschtein et al. 2013) or adult neurogenesis (Bekinschtein et al. 2014b; Reichelt et al. 2016). Infusion of Arc-ASO in Prh $2 \mathrm{~h}$ before the sample phase did not produce any observable deficit in the SLR task for any of the conditions (Fig. 5E, Table 3). One-sample $t$ tests indicate that both Arc-MSO- and Arc-ASO-injected animals were able to learn the s-SLR and I-SLR task $\left(p_{\text {similarmso }}=0.006, t=\right.$ 3.86; $p_{\text {similarASO }}=0.007, t=3.76 ; p_{\text {dissimilarMso }}=0.002$, $t=4.73 ; p_{\text {dissimilarAso }}=0.04, t=2.56$ ). These results indicated that disambiguation of spatial overlapping information does not require Arc in Prh.

\section{Arc expression is necessary for discrimination of overlapping object memories in Prh during a time- restricted window}

Memory consolidation is a time-restricted process, with amnestic agents being effective only during a limited time window (McGaugh, 2000; Winters and Bussey, 2005a). To test whether Arc requirement for LTM of the similar SOR was limited to the first few hours after the sample phase, Arc-ASO was injected into Prh either immediately or $3 \mathrm{~h}$ after the sample phase, and rats were tested $24 \mathrm{~h}$ after acquisition. We found a significant effect of Arc-ASO compared with Arc-MSO when the injection was made immediately after the sample phase, but only for the similar condition (Fig. 6B). One-sample $t$ tests indicated that MSOinjected animals were able to learn both the s-SOR and the d-SOR $\left(p_{\text {similar }}=0.0001, t=6.2 ; p_{\text {dissimilar }}=0.0049, t=\right.$ 4.04), whereas ASO-injected animals learned only the d-SOR version $\left(p_{\text {similar }}=0.43, t=0.81 ; p_{\text {dissimilar }}<0.0001\right.$, $t=9.1$ ). We did not observe any memory impairment in the similar SOR when the Arc-ASO was injected in Prh $3 \mathrm{~h}$ after the sample phase (Fig. $6 B$, bottom), indicating that the effect of Arc-ASO was time-restricted. Injection of the Arc-ASO did not change total exploration times compared with Arc-MSO (see Table 5; paired $t$ test, $p_{\text {similar }}=0.837 ; p_{\text {dissimilar }}=0.654$ ). In addition, one-sample $t$ tests indicated that both ArcMSO- and Arc-ASO-injected animals were able to learn the $\mathrm{s}$-SOR $\left(p_{\text {similarMSO }}=0.009, t=3.75 ; p_{\text {similarAso }}=0.005, t=\right.$ 4.26). The timing of infusion was conducted as previously described for this and other ODNs. The presample time was chosen because ODNs are slowly taken by cells, so for them to have an effect on de novo synthesis, they need to be injected at least $1.5 \mathrm{~h}$ before the experience. Thus, the ODNs injected $3 \mathrm{~h}$ postsample might affect protein synthesis at $\sim 4.5 \mathrm{~h}$ post-sample, when consolidation seems to have 
A

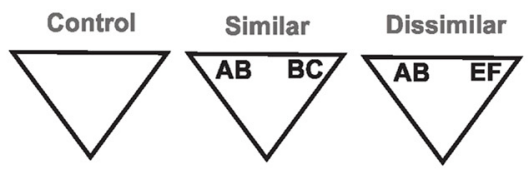

B

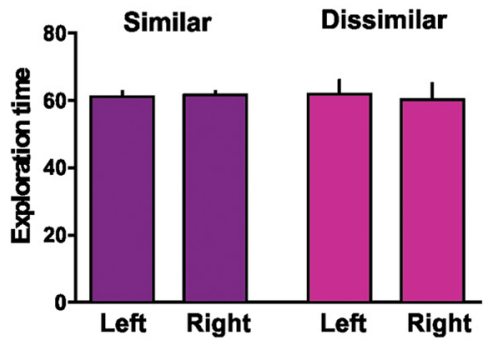

C
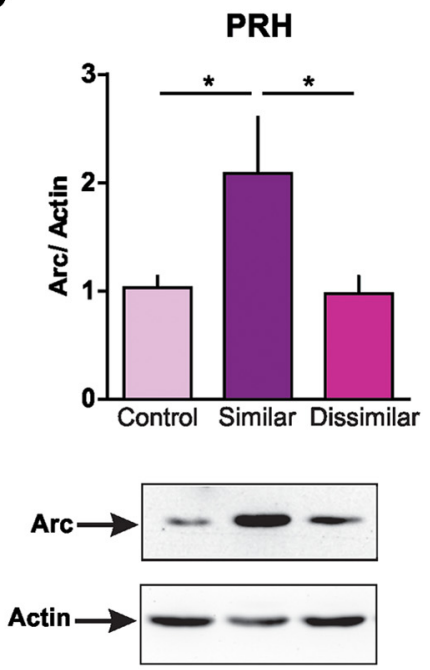

Figure 7. Exploration of similar objects, but not dissimilar objects, is associated with an increase in the protein levels of Arc in the Prh. $\boldsymbol{A}$, Schematic representations of the task configurations. B, Percentage of exploration of the objects used during the similar and dissimilar task, considering the location (left or right) of the object during the task. $\boldsymbol{C}$, Arc protein levels in the Prh after exposure to the objects. One-way ANOVA, $F=3.818, p=0.038, n=8$. Control versus similar: $d=2.407$; Dissimilar versus similar: $d=2.073$. Data are expressed as the mean $\pm \mathrm{SEM} ; *, p<0.05$.

ended. These results are similar to the ones obtained when infusing Arc-ASO into the amygdala to block fear extinction (Onoue et al. 2014): pre-extinction infusion caused an impairment, but infusion $3 \mathrm{~h}$ after extinction training did not produce any effect.

\section{Arc expression in Prh increased as needed}

The findings of these experiments provide compelling evidence that Arc in Prh is involved in the molecular mechanisms underlying the disambiguation of overlapping object memories. Moreover, these findings isolate the action of Arc to the consolidation phase of memory, specifically. Particularly interesting is the finding that postsample injections, made after initial encoding of the to-be-remembered objects, disrupt memory only in the similar SOR but not in the dissimilar SOR. This finding raises the question of whether Arc is expressed equally in both conditions but needed only in the first, or whether Arc is expressed on an "as-needed" basis, that is, spontaneously in response to encountering similar objects, the representations of which need to be separated before storage in memory. We have previously found that BDNF was expressed in this manner in the DG after exposure to similar locations (Bekinschtein et al. 2013).

To test this possibility, we exposed rats to two similar objects or two dissimilar objects within the training arena and a control group to the empty arena (Fig. 7A). One hour after the exposure, rats were killed, and the Prh was dissected and homogenized for Western blot analysis of Arc protein content. There were no differences in total exploration times, and rats spent an equal amount of time exploring each object in the similar and the dissimilar conditions (two-way ANOVA (\%time) $p_{\text {position }}=0.943$, $p_{\text {condition }}=0.673, p_{\text {interaction }}=0.591 ; t$ test (total time) $p=$ 0.943; Fig. 7B). Immunostaining revealed a one-fold increase in Arc expression in the animals exposed to the two similar objects compared with the ones exposed either to the two dissimilar objects or to the empty arena (Fig. 7C). These findings provide evidence that Arc is expressed on an as-needed basis, such that Arc is increased spontaneously when separating the representations of similar objects. Although we tried measuring BDNF, its levels proved difficult to measure because of its low expression in Prh. Nonetheless, BDNF-ASO caused amnesia only for the similar condition, indicating that synthesis of BDNF was required only to consolidate overlapping memories.

\section{BDNF enhances discrimination of overlapping object memories in Prh through Arc expression}

We then asked whether BDNF and Arc expression in Prh during consolidation of overlapping memories were part of the same or different pathways. Because BDNF has been shown to enhance memory consolidation when injected exogenously (Alonso et al. 2002; Peters et al. 2010; Bekinschtein et al. 2013), we reasoned that this putative enhancing effect should be prevented if Arc expression was blocked. In addition, it has been shown previously that hrBDNF induces Arc expression in the hippocampus (Ying et al. 2002; Lee et al. 2004). To be able to see memory enhancement, we brought control animals' performance down to chance levels by making the discrimination more difficult. Thus, we modified the task by making the objects more similar during the sample phase. For this extra-similar SOR (xs-SOR), we used objects made of three features; two of these objects shared two of the features (ABB and $B B C$ ), and the third object was completely different from the other two (EFG; Fig. 8A, see also Fig. 1). We evaluated memory $24 \mathrm{~h}$ after the sample phase using one novel object made of the repeated feature and the other two nonshared features $(A B C)$ and a familiar object (EFG; Fig. $8 B$ ). There were no 
A
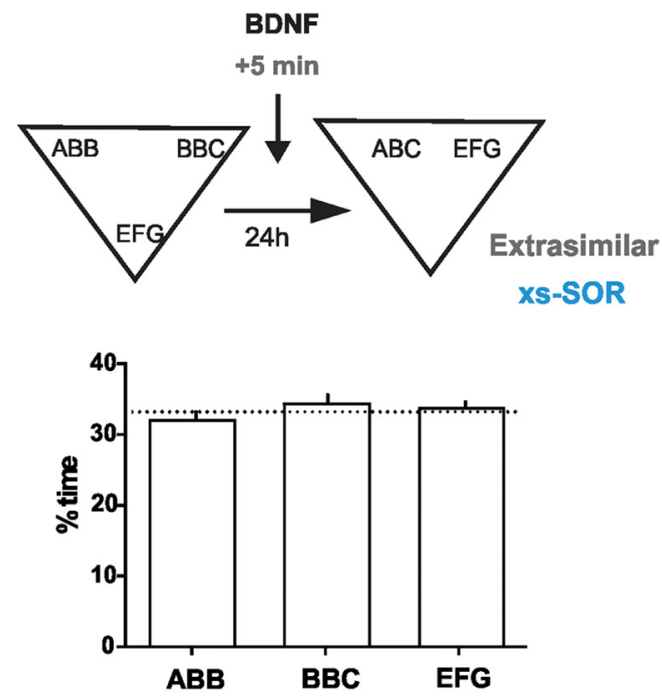

C
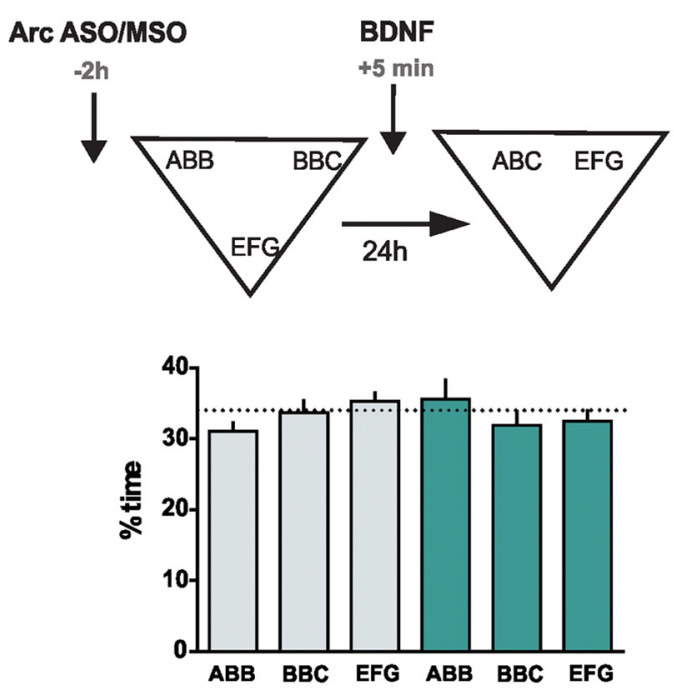

E

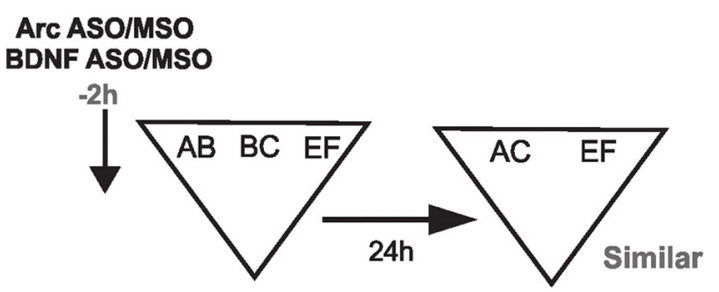

B

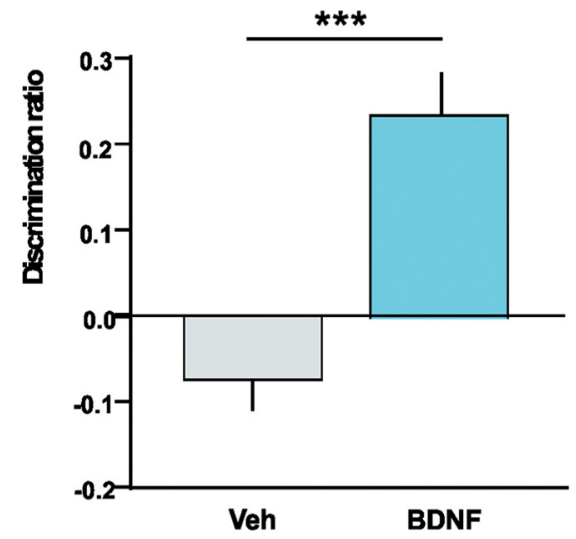

D

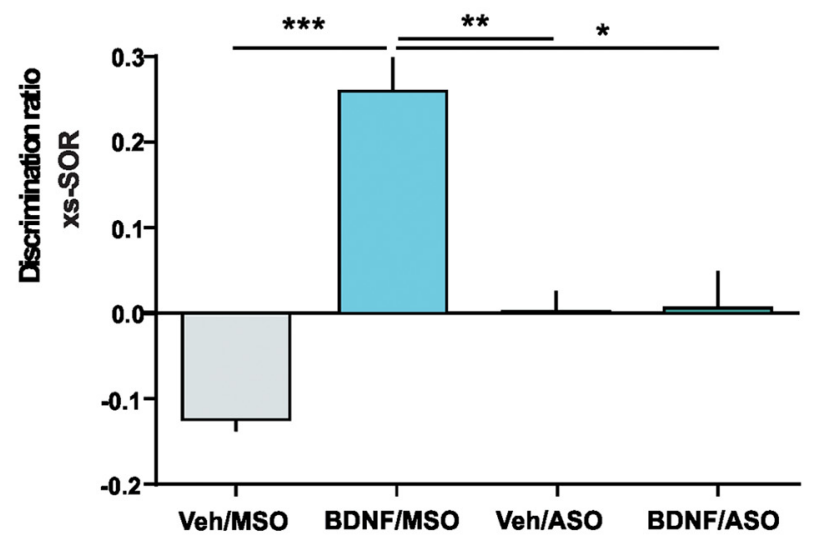

F

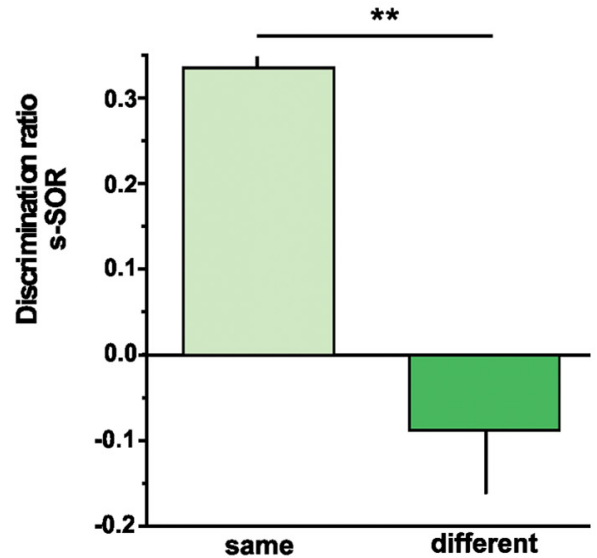

Figure 8. Arc and BDNF molecular pathways interact during consolidation of similar object representations in Prh. $\boldsymbol{A}$, Bottom, percentage of time spent exploring each of the objects in the sample phase in the xs-SOR. One-way ANOVA (\%time), $F=0.845$, 
continued

$p=0.436$. $\boldsymbol{B}$, Rats injected with recombinant BDNF in the Prh 5 min after the sample phase. Unpaired $t$ test $(t=5.224), p=0.0001$, $n=8, d=2.612$. $C$, Percentage of time spent exploring each of the objects in the sample phase in the xs-SOR after the injection of Arc-MSO (light color) or ASO (dark color). Two-way ANOVA (\%time) $F=1.496, p$ (drug) $=0.235 ; F=0.098, p$ (object) $=0.907$; $F=1.358, p$ (interaction) $=0.269$. $D$, Effects of the combined injection of BDNF and Arc-ASO on the discrimination ratio in the xs-SOR. Two-way ANOVA $F=14.95, p(B D N F)=0.001 ; F=1.627, p($ Arc-ASO) $=0.217 ; F=14.29, p$ (interaction) $=0.0012 ; n=6$. BDNF/MSO versus BDNF/ASO: $d=1.796$; Veh/MSO versus BDNF/MSO: $d=1.411$; Veh/ASO versus BDNF/MSO: $d=0.294$. $\boldsymbol{E}$, Schematic illustration of the s-SOR task and infusion time points. $\boldsymbol{F}$, Effects of the injection of an Arc-ASO and BDNF-ASO in the Prh of the same or opposite hemispheres on performance of the s-SOR task. Paired $t$ test $(t=4.338), p=0.0074, n=6, d=7.383$. Data are expressed as the mean $\pm \mathrm{SEM} ; *, p<0.05 ; * *, p<0.01 ; * * *, p<0.001$.

differences in exploration of the three objects during the sample phase, indicating that making two objects even more similar did not affect visual or tactile perception of them (Fig. 8A, bottom, Table 2). The discrimination ratio for control saline-injected rats was not significantly different from zero, indicating that they could not store the representations of the two similar objects as different (Fig. $8 B, p_{\text {xs }}=0.08, t=2.02$, one-sample $t$ test). However, injection of human recombinant BDNF (hrBDNF) into Prh $5 \mathrm{~min}$ after the sample phase enhanced performance compared with the control group (Fig. 8B, Table 3). In addition, a one-sample $t$ test revealed that the discrimination ratio of BDNF-injected animals was significantly different from zero $\left(p_{\mathrm{xsBDNF}}=0.0015, t=5.06\right)$. This indicates that infusion of BDNF into Prh improved the consolidation of overlapping object memories.

To analyze whether Arc expression was required for this enhancing effect of BDNF, we combined injection of hrBDNF with Arc-ASO into Prh. Arc-ASO or Arc-MSO was injected $2 \mathrm{~h}$ before the sample phase, and hrBDNF or saline was injected 5 min after the sample phase (Fig. 8C). There were no differences in exploration time during the sample phase between Arc-ASO- and Arc-MSO-injected animals (Fig. 8C, bottom). Arc-ASO infusion, but not ArcMSO infusion, prevented the BDNF-dependent enhancement in performance during the choice phase conducted the next day (Fig. 8D). In addition, one-sample $t$ tests indicated that the only group with a discrimination ratio significantly above zero was the BDNF/MSO group $\left(p_{\text {Veh/MSO }}=0.0002, t=9.47 ; p_{\text {BDNF/MSO }}=0.03, t=0051\right.$; $\left.p_{\mathrm{Veh} / \mathrm{ASO}}=0.96, t=3.01 ; p_{\mathrm{BDNF} / \mathrm{ASO}}=0.9, t=0.9\right)$. These results indicate that Arc expression is required for BDNFinduced increase in consolidation of highly overlapping memories.

\section{Molecular disconnection suggests that Arc is a critical effector of BDNF during discrimination of overlapping object memories in Prh}

We next sought to determine whether BDNF and Arc interacted during consolidation of the similar SOR task.

Table 2. Total exploration times during the sample sessions for Fig. 8

\begin{tabular}{llll}
\hline Figure & ABB & BBC & EFG \\
$8 A$ & $37.52 \pm 8.03$ & $37.56 \pm 10.46$ & $38.62 \pm 9.59$ \\
$8 C$ & & & \\
$\quad$ Arc-MSO & $36.75 \pm 2.67$ & $39.66 \pm 3.14$ & $41.47 \pm 2.64$ \\
Arc-ASO & $41.80 \pm 2.39$ & $39.02 \pm 3.20$ & $40.01 \pm 3.37$ \\
\hline
\end{tabular}

Thus, we conducted a molecular disconnection experiment. The rationale for this can be found in a typical brain disconnection experiment in which one wants to determine whether two brain structures are connected during a particular behavioral manipulation (Gaffan and Harrison, 1987; Ito et al. 2008). Assuming that the main connections between the two structures are ipsilateral, inactivation of the two regions in the same hemisphere would leave behavior intact, but contralateral inactivation would hamper performance. If, instead of two regions, we think of two molecular or gene expression pathways within a given structure, we can apply a similar line of reasoning. If the two molecular pathways interact to produce behavior, then blocking both of them in that region of one hemisphere would not have any effect, but blockade of one molecule in one hemisphere and the second molecule in the other hemisphere would produce a deficit.

Thus, to evaluate whether BDNF and Arc signaling pathways are connected in Prh, we blocked BDNF and Arc expression in the Prh of the same hemisphere or blocked BDNF expression in the Prh of one hemisphere and Arc expression in the Prh of the other hemisphere (Fig. 8E). We found no effect in the similar SOR task evaluated at $24 \mathrm{~h}$ if BDNF-ASO and Arc-ASO were injected into the same Prh, while injecting BDNF-MSO and Arc-MSO into the other Prh $2 \mathrm{~h}$ before the sample phase (Fig. 8F). However, when BDNF-ASO/Arc-MSO and BDNF-MSO/Arc-ASO were injected into Prh in different hemispheres, there was a significant impairment in the similar SOR task (Fig. 8F). There were no differences in total exploration times between the two groups (see Table 3). In addition, one-sample $t$ tests revealed that the discrimination ratio from the "same" group was different from zero, whereas the discrimination ratio from the "different" group was not $\left(p_{\text {same }}=0.0023, t=\right.$ 5.73; $p_{\text {different }}=0.29, t=1.17$ ). This result suggests that BDNF and Arc interact during consolidation of overlapping memories in Prh.

\section{Discussion}

In this work, we have shown that BDNF and Arc are required for consolidation of overlapping object memories in Prh. Several of our results point at the BDNF-Arc pathway as an important player underlying disambiguation of overlapping object representations: (1) Both BDNF and Arc-ASO impaired memory only for the similar condition of the SOR task; (2) the effect of Arc-ASO is time restricted, suggesting that Arc is mainly involved in consolidation; (3) the amnesia caused by Arc-ASO is depen- 
Table 3. Total exploration times during the choice session of the SOR and SLR tasks

\begin{tabular}{|c|c|c|}
\hline Fig. $2 B$ & Novel & Familiar \\
\hline Similar & $24.9 \pm 1.6$ & $15.6 \pm 1.3$ \\
\hline Dissimilar & $32.3 \pm 2.6$ & $15.4 \pm 1.8$ \\
\hline \multicolumn{3}{|l|}{$2 C$} \\
\hline Familiar condition & $28.4 \pm 2.2$ & $27.0 \pm 3.2$ \\
\hline Novel condition & $32.5 \pm 3.2$ & $23.6 \pm 1.6$ \\
\hline \multicolumn{3}{|l|}{$3 D, E$} \\
\hline \multicolumn{3}{|l|}{ s-SOR } \\
\hline BDNF-MSO & $30.5 \pm 2.8$ & $20.2 \pm 2.4$ \\
\hline BDNF-ASO & $23.5 \pm 4.7$ & $28.3 \pm 4.3$ \\
\hline \multicolumn{3}{|l|}{ d-SOR } \\
\hline BDNF-MSO & $37.3 \pm 3.1$ & $20.2 \pm 2.1$ \\
\hline BDNF-ASO & $38.3 \pm 3.7$ & $24.2 \pm 2.7$ \\
\hline \multicolumn{3}{|l|}{$3 F, G$} \\
\hline \multicolumn{3}{|l|}{ s-SOR } \\
\hline Vehicle & $31.6 \pm 3.6$ & $19.7 \pm 2.2$ \\
\hline Emetine & $23.3 \pm 3.9$ & $29.1 \pm 3.3$ \\
\hline \multicolumn{3}{|l|}{ d-SOR } \\
\hline Vehicle & $38.8 \pm 4.5$ & $22.0 \pm 2.5$ \\
\hline Emetine & $28.9 \pm 4.0$ & $19.1 \pm 2.2$ \\
\hline \multicolumn{3}{|l|}{$4 C$, left } \\
\hline \multicolumn{3}{|l|}{ s-SOR } \\
\hline Arc-MSO & $20 \pm 0.9$ & $12.8 \pm 0.7$ \\
\hline Arc-ASO & $16.5 \pm 1.7$ & $20.0 \pm 1.8$ \\
\hline \multicolumn{3}{|l|}{$4 C$, right } \\
\hline \multicolumn{3}{|l|}{ d-SOR } \\
\hline Arc-MSO & $28.9 \pm 3.0$ & $17.3 \pm 2.9$ \\
\hline Arc-ASO & $32.4 \pm 4.7$ & $18.1 \pm 2.8$ \\
\hline \multicolumn{3}{|l|}{$5 E$} \\
\hline \multicolumn{3}{|l|}{ s-SLR } \\
\hline Arc-MSO & $36.5 \pm 4.7$ & $26.0 \pm 3.6$ \\
\hline Arc-ASO & $39.6 \pm 5.8$ & $24.5 \pm 2.0$ \\
\hline \multicolumn{3}{|l|}{ I-SLR } \\
\hline Arc-MSO & $30.5 \pm 3.8$ & $19.6 \pm 2.0$ \\
\hline Arc-ASO & $34.3 \pm 4.3$ & $24.6 \pm 5.3$ \\
\hline \multicolumn{3}{|l|}{$6 B$} \\
\hline \multicolumn{3}{|l|}{ s-SOR } \\
\hline \multicolumn{3}{|l|}{$5 \mathrm{~min}$} \\
\hline Arc-MSO & $28.0 \pm 3.2$ & $18.0 \pm 2.2$ \\
\hline Arc-ASO & $23.0 \pm 2.4$ & $21.9 \pm 3.0$ \\
\hline $3 \mathrm{~h}$ & & \\
\hline Arc-MSO & $25.66 \pm 4.50$ & $13.65 \pm 1.26$ \\
\hline Arc-ASO & $28.96 \pm 3.96$ & $17.29 \pm 1.92$ \\
\hline d-SOR & & \\
\hline $5 \min$ & & \\
\hline Arc-MSO & $41.8 \pm 3.4$ & $25.0 \pm 2.4$ \\
\hline Arc-ASO & $38.1 \pm 6.2$ & $22.8 \pm 3.2$ \\
\hline $8 B$ & & \\
\hline xs-SOR & & \\
\hline Vehicle & $32.3 \pm 2.5$ & $33.1 \pm 4.4$ \\
\hline BDNF & $33.7 \pm 4.8$ & $22.0 \pm 2.2$ \\
\hline $8 D$ & & \\
\hline Vehicle & & \\
\hline Arc-MSO & $25.8 \pm 3.1$ & $32.8 \pm 3.4$ \\
\hline Arc-ASO & $28.2 \pm 3.5$ & $27.7 \pm 3.0$ \\
\hline BDNF & & \\
\hline Arc-MSO & $32.3 \pm 2.1$ & $19.9 \pm 3.0$ \\
\hline Arc-ASO & $29.1 \pm 1.9$ & $28.7 \pm 2.0$ \\
\hline $8 F$ & & \\
\hline s-SOR & & \\
\hline Same & $37.4 \pm 6.5$ & $19.0 \pm 4.0$ \\
\hline Different & $19.5 \pm 1.6$ & $24.0 \pm 3.1$ \\
\hline
\end{tabular}

Results are expressed as mean \pm SEM in seconds. Novel and familiar indicate to which of the two objects present during the choice phase the exploration time corresponds (novel location/identity object or familiar location/ identity object).

dent on the delay between sample and choice, not affecting memory at short delays such as $3 \mathrm{~h}$, but causing
Table 4. Total exploration times during the choice session of the SOR task

\begin{tabular}{lll}
\hline Figure & $p$ value & $t_{\text {total }}$ \\
$2 B$ & 0.1100 & \\
Similar & & $40.66 \pm 2.82$ \\
Dissimilar & & $47.77 \pm 2.02$ \\
$2 C$ & 0.3593 & \\
$\quad$ Familiar & & $60.76 \pm 4.30$ \\
$\quad$ Novel & & $53.1 \pm 7.21$ \\
3C & 0.902 & $T$ total \\
S-SOR & & $50.66 \pm 4.17$ \\
$\quad$ MSO & & $51.80 \pm 8.92$ \\
ASO & 0.354 & \\
d-SOR & & $57.53 \pm 5.41$ \\
MSO & & $62.47 \pm 5.16$ \\
ASO & &
\end{tabular}

$3 D$

S-SOR

MSO

ASO

0.823

d-SOR

MSO

ASO

$4 C$

s-SOR

MSO

ASO

d-SOR

MSO

ASO

$5 A$

MSO

ASO

$5 E$

S-SOR

MSO

ASO

d-SOR

MSO

ASO

$6 B$, upper

s-SOR

MSO

ASO

d-SOR

MSO

ASO

$6 B$, lower

s-SLR

MSO

ASO

$8 B$

MSO

ASO

$8 F$

$\mathrm{MSO}$

ASO

$8 D$

0.077

$51.23 \pm 5.52$

$52.40 \pm 6.26$

$60.80 \pm 6.51$

$48.01 \pm 5.56$

0.2059

$32.84 \pm 1.16$

$36.47 \pm 2.76$

0.8750

$39.18 \pm 3.21$

$38.65 \pm 2.81$

$46.22 \pm 5.05$

$50.50 \pm 5.66$

0.419

$63.61+6.89$

$55.00 \pm 6.38$

$50.10 \pm 5.28$

$58.95 \pm 8.30$

0.837

$46.02 \pm 5.13$

$44.92 \pm 5.05$

0.654

$65.28 \pm 5.47$

$62.50 \pm 7.70$

0.663

$39.31 \pm 12.78$

$46.25 \pm 5.39$

0.173

$68.37 \pm 5.98$

$55.73 \pm 6.41$

$56.48 \pm 9.63$

$43.59 \pm 3.50$

$58.59 \pm 6.47$

$55.88 \pm 6.60$

$52.19 \pm 3.93$

$57.85 \pm 2.96$

Results are expressed as mean \pm SEM in seconds. $p$ values are for the comparison between total exploration times during the choice session for each experimental group depicted in the same row. Paired $t$ test was used for these comparisons, except in the case of Fig. $8 B, D$, for which unpaired $t$ test and one-way ANOVA were used.

amnesia at $24 \mathrm{~h}$; (4) Arc is expressed in an as-needed manner after encountering similar objects; (5) Arc in Prh is 
Table 5. Total exploration times during the sample session of the SOR task

\begin{tabular}{|c|c|}
\hline $\begin{array}{l}\text { Figure } \\
2 B\end{array}$ & $t_{\text {total }}$ \\
\hline Similar & $106.4 \pm 6.16$ \\
\hline Dissimilar & $106.4 \pm 6.73$ \\
\hline \multicolumn{2}{|l|}{$2 C$} \\
\hline Familiar & $113 \pm 14.20$ \\
\hline Novel & $97.81 \pm 12.74$ \\
\hline \multicolumn{2}{|l|}{$3 C$} \\
\hline \multicolumn{2}{|l|}{ s-SOR } \\
\hline BDNF-MSO & $89.49 \pm 8.86$ \\
\hline BDNF-ASO & $90.65 \pm 14.98$ \\
\hline \multicolumn{2}{|l|}{ d-SOR } \\
\hline BDNF-MSO & $73.97 \pm 9.18$ \\
\hline BDNF-ASO & $78.33 \pm 9.14$ \\
\hline \multicolumn{2}{|l|}{$3 D$} \\
\hline s-SOR & Veh \\
\hline Vehicle & $86.62 \pm 8.58$ \\
\hline Emetine & $85.91 \pm 12.36$ \\
\hline \multicolumn{2}{|l|}{ d-SOR } \\
\hline Vehicle & $94.88 \pm 9.26$ \\
\hline Emetine & $96.83 \pm 11.71$ \\
\hline \multicolumn{2}{|l|}{$4 B$} \\
\hline \multicolumn{2}{|l|}{ s-SOR } \\
\hline Arc-MSO & $107 \pm 9.56$ \\
\hline Arc-ASO & $114.7 \pm 10.68$ \\
\hline \multicolumn{2}{|l|}{ d-SOR } \\
\hline Arc-MSO & $108.7 \pm 7.25$ \\
\hline Arc-ASO & $120.7 \pm 5.62$ \\
\hline \multicolumn{2}{|l|}{$8 A$} \\
\hline Vehicle & $120.7 \pm 4.57$ \\
\hline BDNF & $114 \pm 10.12$ \\
\hline \multicolumn{2}{|l|}{$8 C$} \\
\hline \multicolumn{2}{|l|}{ Vehicle } \\
\hline MSO & $108.3 \pm 9.80$ \\
\hline ASO & $118.5 \pm 10.97$ \\
\hline \multicolumn{2}{|l|}{ BDNF } \\
\hline MSO & $129.5 \pm 4.30$ \\
\hline ASO & $123.7 \pm 8.86$ \\
\hline
\end{tabular}

Results are expressed as mean \pm SEM in seconds.

not required for acquisition/consolidation of overlapping spatial memories, indicating that these molecular processes in this structure are dependent on the type of representations that are necessary to solve the task; (6) the memory enhancement induced by hrBDNF is abolished completely by Arc-ASO, suggesting that Arc is one of the molecules required for the effect of BDNF; and finally, (7) BDNF and Arc molecular pathways interact during acquisition/consolidation of overlapping object memories as shown by the molecular disconnection experiment.

We used a modified version of the spontaneous object recognition task, and thus, there could be a concern regarding a change in motivation to explore the objects after a particular pharmacological manipulation (i.e., manipulations could change the animals' preference for novel items to familiar items). In our experiments, this factor could not account for the differences in the discrimination ratios, because that would mean that our manipulations of the Prh somehow affected motivation only in the similar condition but not in the dissimilar condition. Moreover, the fact that infusion of the Arc-ASO $3 \mathrm{~h}$ after the sample phase did not affect novelty preference in the similar SOR condition effectively rules out the possibility that a change in motivation explains these results. Also, infusion of ODNs in Prh did not change exploration or cause memory impairment in a spatial object exploration task. In the experiment depicted in Fig. $3 C$, BDNF-ASO-treated animals showed a negative discrimination ratio. We have seen these type of results before using our spatial discrimination task (Bekinschtein et al. 2013), and it could be explained if the animals could not store separate representations of the two similar objects; then during the choice phase, it might seem that the novel object (made of two familiar features) would have been explored twice as long during sample, increasing familiarity during test.

These results indicate that BDNF and Arc take part in a protein synthesis-dependent mechanism important for consolidation of certain types of memories. This is remarkably similar to our findings in the DG of the hippocampus (Bekinschtein et al. 2013). Our results also suggest that there is interaction between BDNF and Arc during consolidation of overlapping object memories, indicating that Arc is likely an effector of the plasticity induced by BDNF. Importantly, we compared the similar and dissimilar conditions for all experiments, and the memory test was always conducted after the same delay for both of them (i.e., $24 \mathrm{~h}$ after acquisition). Because the effects were observed only for the similar condition, they were dependent on the similarity, but not on the delay of testing. Thus, these mechanisms are specifically involved in discrimination of overlapping memories, but not on their persistence. However, we cannot conclude from these results that BDNF and Arc are not involved in the mechanisms of longer-lasting maintenance of nonoverlapping memories in Prh or that other known plasticity molecules such as Zif268 are required for consolidation of nonoverlapping memories in this structure.

There is convincing evidence to indicate that Prh, rather than storing simple features of objects, stores conjunctive representations that can later be used to disambiguate particular objects during memory retrieval. This hypothesis has been previously tested by examining the role of Prh during discrimination of objects that shared overlapping features at the moment of retrieval (Norman and Eacott, 2004; Bartko et al. 2007). In this sense, Prh could be thought of as a structure that acts as a "pattern separator" for representations of objects, disambiguating overlapping information into separate and less confusable representations. In fact, recordings of single units from the Prh showed populations of neurons whose firing rate changed gradually as the originally learned objects were ambiguously morphed to varying degrees, and other neurons whose firing rate changed abruptly according to the rewarded response categories associated with the objects. They suggest that this abrupt change in the firing rate could be a result of the orthogonalization of the original morphing continuum (Ahn and Lee, 2017). This neural perirhinal population with orthogonalized responses that correlate with their memory-guided choices could be the neural substrate that supports the consoli- 
dation of similar objects into nonoverlapping representations that guide behavior in the SOR task.

Our experiments suggest that, at least for storage of object representations, but not of spatial representations, BDNF and Arc are essential for consolidation of separate memories and a part of a time-restricted, protein synthesis-dependent mechanism of memory stabilization in Prh. These results are in line with the evidence indicating that structures in the medial temporal lobe are specialized in processing different types of representations. Because the Prh receives prominent afferents from the ventral visual stream (the "what" pathway), it has been suggested to be at the top of a hierarchical network of object processing (Kent et al. 2016). This idea is compatible with the thought of Prh being a pattern separation structure. On the other hand, the postrhinal cortex $(\mathrm{Pc})$ lies posterior to the Prh and receives afferent projections primarily from the dorsal ("where") processing system (Suzuki and Amaral, 1994) that has been implicated in visuospatial processing (Kravitz et al. 2011). Because the "what" and "where" features are essential to episodic memory, information from Prh and $\mathrm{Pc}$ has to be integrated into an experience. In fact, efferents from these structures project preferentially to different regions of the entorhinal cortex (EC), which, in turn, project to the hippocampus (Witter, 2007). Although Prh primarily projects to the lateral entorhinal cortex (LEC), the Pc projects to the medial entorhinal cortex (MEC; Suzuki and Amaral, 1994). This pattern of connectivity suggests a segregation of object and spatial information processing in EC that could be integrated within the EC or in the hippocampus via the perforant path (Witter, 2007). Thus, plasticity in the Prh could occur at the synapses connecting to the LEC, facilitating object information processing necessary for episodic memory. It is highly unlikely that our manipulation of Prh, such as infusion of ASO, reached Pc, since the infusion site was far away from this structure, and we observed no spreading of the oligonucleotides outside Prh.

It is widely believed that changes in synaptic strength support long-term memory storage in the brain (Kandel, 2001). In vitro studies have found that Prh neurons can develop both long-term potentiation (LTP) and long-term depression (LTD; Bilkey, 1996; Ziakopoulos et al. 1999; Cho et al. 2000; Massey et al. 2001). In vivo experiments have strongly associated object recognition memory with LTD induction and maintenance in Prh (Griffiths et al. 2008). This type of plasticity has been found to be dependent on internalization of AMPA receptors in Prh. In this sense, Arc KO mice have deficits in many learning tasks, including object recognition, and they have diminished LTD in the hippocampus (Plath et al. 2006). In another study, Jakkamsetti et al. (2013) observed that Arcexpressing neurons preferentially develop LTD in response to activation of group I metabotropic receptors in $\mathrm{CA} 1$, and that this molecule is required for mGlurRdependent LTD. It is possible that similar mechanisms are involved in Arc-dependent consolidation of overlapping object memories in our behavioral paradigm. Arc has been implicated in AMPA receptor trafficking at the synapses (Rial Verde et al. 2006; Shepherd et al. 2006;
Waung et al. 2008); thus it seems logical that this could be a possible mechanism for object memory storage in Prh.

One previous study used BDNF-ASO to block BDNF expression in Prh either before or after the sample phase in a spontaneous object recognition paradigm (Seoane et al. 2012). BDNF-ASO injected $1 \mathrm{~h}$ before or immediately after acquisition impaired familiarity discrimination at $24 \mathrm{~h}$, but not 20 min, after acquisition. Infusion of the ASO $6 \mathrm{~h}$ postacquisition did not impair memory $24 \mathrm{~h}$ later. However, we believe the results of our study do not generalize to the molecular mechanisms of recognition memory but rather the mechanisms underlying storage of unique representations of objects in Prh. In our experiments, we found a memory impairment caused by BDNF-ASO only in the similar, but not in the dissimilar, condition. Our results are consistent with a role of Prh in storage of nonconfusable object representations.

Given that adult neurogenesis in the DG has been implicated in the discrimination of overlapping spatial representations (Clelland et al. 2009; Kheirbek et al. 2012; Nakashiba et al. 2012; Bekinschtein et al. 2014b) and that adult neurogenesis is absent in Prh, it is clear that the underlying cellular mechanisms of pattern separation are different between structures such as the DG and Prh. However, despite these anatomic differences, several molecular mechanisms that influence plasticity changes at synapses seem to be similar and common to memory storage processes. Synaptic mechanisms for memory consolidation are widely conserved across species despite the differences in their brain anatomy. Molecules such as CAMP response element-binding protein (CREB) are essential in consolidation of many types of learning in invertebrates and vertebrates (Carew and Sahley, 1986; Abel and Lattal, 2001; Schafe et al. 2001; Barco et al. 2006), and compounds such as BDNF are important parts of the machinery involved in plasticity of many sorts, from synaptic plasticity and memory to development and pain (Lu and Chow, 1999; McAllister et al. 1999; Bramham and Messaoudi, 2005; Pezet and McMahon, 2006; Bekinschtein et al. 2008). Thus, from an evolutionary perspective, it seems logical that different regions of the brain became specialized to process particular types of representations, but the underlying plasticity mechanisms were conserved. In light of this argument, it makes sense that some of the main players in the intracellular molecular plasticity mechanisms driving consolidation of overlapping memories appear to be identical across different brain regions. Adult neurogenesis, therefore, might have evolved at least in part as a cellular mechanism that prevents interference specifically between spatial and episodic representations-and not representations involving only objectsbecause the increased excitability and plasticity of adultborn neurons in the DG is necessary for the processing of highly complex information present in places and episodes.

To our knowledge, the present study is the first to provide evidence regarding the molecular pathways involved in the consolidation of overlapping memories outside the DG and, together with our previous studies, to demonstrate that BDNF is an important plasticity mole- 
cule involved in this process in multiple brain regions. In addition, we show, for the first time, that under certain conditions Arc protein is required for spontaneous object recognition in Prh and, in particular, for storage of separated representations of overlapping objects. Our results point toward an evolutionary convergence of the molecular mechanisms involved in plasticity required for storage of unique representations across different regions of the brain. Importantly, these molecular mechanisms are not general to all conditions of object (or location) recognition; they were required only when similar memories had to be kept distinct.

\section{References}

Abel T, Lattal KM (2001) Molecular mechanisms of memory acquisition, consolidation and retrieval. Curr Opin Neurobiol 11:180-187. Medline

Ahn JR, Lee I (2017) Neural correlates of both perception and memory for objects in the rodent perirhinal cortex. Cereb Cortex 27:3856-3868.

Alonso M, Vianna MR, Depino AM, Mello e Souza T, Pereira P, Szapiro G, Viola H, Pitossi F, Izquierdo I, Medina JH (2002) BDNFtriggered events in the rat hippocampus are required for both short- and long-term memory formation. Hippocampus 12:551560. CrossRef

Barco A, Bailey CH, Kandel ER (2006) Common molecular mechanisms in explicit and implicit memory. J Neurochem 97:15201533. CrossRef Medline

Bartko SJ, Winters BD, Cowell RA, Saksida LM, Bussey TJ (2007) Perirhinal cortex resolves feature ambiguity in configural object recognition and perceptual oddity tasks. Learn Mem 14:821-832. CrossRef Medline

Bartko SJ, Cowell RA, Winters BD, Bussey TJ, Saksida LM (2010) Heightened susceptibility to interference in an animal model of amnesia: impairment in encoding, storage, retrieval-or all three? Neuropsychologia 48:2987-2997. CrossRef

Bekinschtein P, Cammarota M, Medina JH (2014a) BDNF and memory processing. Neuropharmacology 76(Pt C):677-683. CrossRef Medline

Bekinschtein P, Cammarota M, Izquierdo I, Medina JH (2008) BDNF and memory formation and storage. Neuroscientist 14:147-156. CrossRef Medline

Bekinschtein P, Cammarota M, Igaz LM, Bevilaqua LR, Izquierdo I, Medina JH (2007) Persistence of long-term memory storage requires a late protein synthesis- and BDNF-dependent phase in the hippocampus. Neuron 53:261-277. CrossRef Medline

Bekinschtein P, Kent BA, Oomen CA, Clemenson GD, Gage FH, Saksida LM, Bussey TJ (2013) BDNF in the dentate gyrus is required for consolidation of "pattern-separated" memories. Cell Rep 5:759-768. CrossRef Medline

Bekinschtein P, Kent BA, Oomen CA, Clemenson GD, Gage FH, Saksida LM, Bussey TJ (2014b) Brain-derived neurotrophic factor interacts with adult-born immature cells in the dentate gyrus during consolidation of overlapping memories. Hippocampus 24:905911.

Bilkey DK (1996) Long-term potentiation in the in vitro perirhinal cortex displays associative properties. Brain Res 733:297-300. Medline

Bramham CR, Messaoudi E (2005) BDNF function in adult synaptic plasticity: the synaptic consolidation hypothesis. Prog Neurobiol 76:99-125. CrossRef Medline

Bramham CR, Alme MN, Bittins M, Kuipers SD, Nair RR, Pai B, Panja D, Schubert M, Soule J, Tiron A, Wibrand K (2010) The arc of synaptic memory. Exp Brain Res 200:125-140. CrossRef Medline

Bussey TJ, Saksida LM, Murray EA (2002) Perirhinal cortex resolves feature ambiguity in complex visual discriminations. Eur J Neurosci 15:365-374. Medline
Carew TJ, Sahley CL (1986) Invertebrate learning and memory: from behavior to molecules. Annu Rev Neurosci 9:435-487. CrossRef Medline

Clelland CD, Choi M, Romberg C, Clemenson GD, Jr., Fragniere A, Tyers $P$, Jessberger S, Saksida LM, Barker RA, Gage FH, Bussey TJ (2009) A functional role for adult hippocampal neurogenesis in spatial pattern separation. Science 325:210-213. CrossRef

Creer DJ, Romberg C, Saksida LM, van Praag H, Bussey TJ (2010) Running enhances spatial pattern separation in mice. Proc Natl Acad Sci U S A 107:2367-2372. CrossRef Medline

Cho K, Kemp N, Noel J, Aggleton JP, Brown MW, Bashir ZI (2000) A new form of long-term depression in the perirhinal cortex. Nat Neurosci 3:150-156. CrossRef Medline

Davis HP, Squire LR (1984) Protein synthesis and memory: a review. Psychol Bull 96:518-559. Medline

Ennaceur A, Delacour J (1988) A new one-trial test for neurobiological studies of memory in rats. 1: Behavioral data. Behav. Brain Res 31:47-59. CrossRef

Gaffan D, Harrison S (1987) Amygdalectomy and disconnection in visual learning for auditory secondary reinforcement by monkeys. J Neurosci 7:2285-2292. Medline

Gilbert PE, Kesner RP, DeCoteau WE (1998) Memory for spatial location: role of the hippocampus in mediating spatial pattern separation. J Neurosci 18:804-810. Medline

Griffiths S, Scott H, Glover C, Bienemann A, Ghorbel MT, Uney J, Brown MW, Warburton EC, Bashir ZI (2008) Expression of longterm depression underlies visual recognition memory. Neuron 58: 186-194. CrossRef Medline

Guzowski JF, Timlin JA, Roysam B, McNaughton BL, Worley PF, Barnes CA (2005) Mapping behaviorally relevant neural circuits with immediate-early gene expression. Curr Opin Neurobiol 15: 599-606. CrossRef Medline

Ito R, Robbins TW, Pennartz CM, Everitt BJ (2008) Functional interaction between the hippocampus and nucleus accumbens shell is necessary for the acquisition of appetitive spatial context conditioning. J Neurosci 28:6950-6959. CrossRef Medline

Jakkamsetti V, Tsai NP, Gross C, Molinaro G, Collins KA, Nicoletti F, Wang KH, Osten P, Bassell GJ, Gibson JR, Huber KM (2013) Experience-induced Arc/Arg3.1 primes CA1 pyramidal neurons for metabotropic glutamate receptor-dependent long-term synaptic depression. Neuron 80:72-79. CrossRef Medline

Johnson SA, Turner SM, Santacroce LA, Carty KN, Shafiq L, Bizon JL, Maurer AP, Burke SN (2017) Rodent age-related impairments in discriminating perceptually similar objects parallel those observed in humans. Hippocampus 27:759-776. CrossRef Medline

Kandel ER (2001) The molecular biology of memory storage: a dialogue between genes and synapses. Science 294:1030-1038. CrossRef Medline

Kent BA, Hvoslef-Eide M, Saksida LM, Bussey TJ (2016) The representational-hierarchical view of pattern separation: Not just hippocampus, not just space, not just memory? Neurobiol Learn Mem 129:99-106. CrossRef

Kheirbek MA, Tannenholz L, Hen R (2012) NR2B-dependent plasticity of adult-born granule cells is necessary for context discrimination. J Neurosci 32:8696-8702. CrossRef Medline

Kirwan CB, Stark CE (2007) Overcoming interference: an fMRI investigation of pattern separation in the medial temporal lobe. Learn Mem 14:625-633. CrossRef Medline

Kravitz DJ, Saleem KS, Baker Cl, Mishkin M (2011) A new neural framework for visuospatial processing. Nat Rev Neurosci 12:217230. CrossRef Medline

Lee JL, Everitt BJ, Thomas KL (2004) Independent cellular processes for hippocampal memory consolidation and reconsolidation. Science 304:839-843. CrossRef Medline

Leutgeb JK, Leutgeb S, Moser MB, Moser El (2007) Pattern separation in the dentate gyrus and CA3 of the hippocampus. Science 315:961-966. CrossRef Medline

Lu B, Chow A (1999) Neurotrophins and hippocampal synaptic transmission and plasticity. J Neurosci Res 58:76-87. Medline 
Marr D (1971) Simple memory: a theory for archicortex. Philos Trans R Soc Lond B Biol Sci 262:23-81. Medline

Martínez MC, Alen N, Ballarini F, Moncada D, Viola H (2012) Memory traces compete under regimes of limited Arc protein synthesis: implications for memory interference. Neurobiol Learn Mem 98: 165-173. CrossRef Medline

Massey PV, Bhabra G, Cho K, Brown MW, Bashir ZI (2001) Activation of muscarinic receptors induces protein synthesis-dependent long-lasting depression in the perirhinal cortex. Eur $\mathrm{J}$ Neurosci 14:145-152. Medline

McAllister AK, Katz LC, Lo DC (1999) Neurotrophins and synaptic plasticity. Annu Rev Neurosci 22:295-318. CrossRef Medline

McClelland JL, McNaughton BL, O'Reilly RC (1995) Why there are complementary learning systems in the hippocampus and neocortex: insights from the successes and failures of connectionist models of learning and memory. Psychol Rev 102:419-457. Medline

McGaugh JL (2000) Memory-a century of consolidation. Science 287:248-251. Medline

Messaoudi E, Kanhema T, Soule J, Tiron A, Dagyte G, da Silva B, Bramham CR (2007) Sustained Arc/Arg3.1 synthesis controls long-term potentiation consolidation through regulation of local actin polymerization in the dentate gyrus in vivo. J Neurosci 27: 10445-10455. CrossRef

Nakashiba T, Cushman JD, Pelkey KA, Renaudineau S, Buhl DL, McHugh TJ, Rodriguez Barrera V, Chittajallu R, Iwamoto KS, McBain CJ, Fanselow MS, Tonegawa S (2012) Young dentate granule cells mediate pattern separation, whereas old granule cells facilitate pattern completion. Cell 149:188-201. CrossRef Medline

Nakayama D, Iwata $H$, Teshirogi C, Ikegaya $Y$, Matsuki N, Nomura $H$ (2015) Long-delayed expression of the immediate early gene Arc/ Arg3.1 refines neuronal circuits to perpetuate fear memory. J Neurosci 35:819-830. CrossRef Medline

Neunuebel JP, Knierim JJ (2014) CA3 retrieves coherent representations from degraded input: direct evidence for CA3 pattern completion and dentate gyrus pattern separation. Neuron 81:416427. CrossRef Medline

Norman G, Eacott MJ (2004) Impaired object recognition with increasing levels of feature ambiguity in rats with perirhinal cortex lesions. Behav Brain Res 148:79-91. Medline

Onoue K, Nakayama D, Ikegaya Y, Matsuki N, Nomura H (2014) Fear extinction requires Arc/Arg3.1 expression in the basolateral amygdala. Mol Brain 7:30. CrossRef Medline

Paxinos G, Watson C (1998) The rat brain in stereotaxic coordinates, 4th Edition. San Diego: Academic Press.

Peters J, Dieppa-Perea LM, Melendez LM, Quirk GJ (2010) Induction of fear extinction with hippocampal-infralimbic BDNF. Science 328:1288-1290. CrossRef Medline

Pezet S, McMahon SB (2006) Neurotrophins: mediators and modulators of pain. Annu Rev Neurosci 29:507-538. CrossRef Medline

Plath N, et al. (2006) Arc/Arg3.1 is essential for the consolidation of synaptic plasticity and memories. Neuron 52:437-444. CrossRef Medline

Ploski JE, Pierre VJ, Smucny J, Park K, Monsey MS, Overeem KA, Schafe GE (2008) The activity-regulated cytoskeletal-associated protein (Arc/Arg3.1) is required for memory consolidation of pavlovian fear conditioning in the lateral amygdala. J Neurosci 28: 12383-12395. CrossRef Medline

Ranganath C (2010) A unified framework for the functional organization of the medial temporal lobes and the phenomenology of episodic memory. Hippocampus 20:1263-1290. CrossRef Medline
Reichelt AC, Morris MJ, Westbrook RF (2016) Daily access to sucrose impairs aspects of spatial memory tasks reliant on pattern separation and neural proliferation in rats. Learn Mem 23:386-390. CrossRef Medline

Rial Verde EM, Lee-Osbourne J, Worley PF, Malinow R, Cline HT (2006) Increased expression of the immediate-early gene arc/ arg3.1 reduces AMPA receptor-mediated synaptic transmission. Neuron 52:461-474. CrossRef Medline

Schafe GE, Nader K, Blair HT, LeDoux JE (2001) Memory consolidation of Pavlovian fear conditioning: a cellular and molecular perspective. Trends Neurosci 24:540-546. CrossRef

Seoane A, Tinsley CJ, Brown MW (2012) Interfering with Fos expression in rat perirhinal cortex impairs recognition memory. Hippocampus 22:2101-2113. CrossRef Medline

Shepherd JD, Rumbaugh G, Wu J, Chowdhury S, Plath N, Kuhl D, Huganir RL, Worley PF (2006) Arc/Arg3.1 mediates homeostatic synaptic scaling of AMPA receptors. Neuron 52:475-484. CrossRef Medline

Slipczuk L, Bekinschtein P, Katche C, Cammarota M, Izquierdo I, Medina JH (2009) BDNF activates mTOR to regulate GluR1 expression required for memory formation. PLoS ONE 4:e6007. CrossRef Medline

Suzuki WA, Amaral DG (1994) Perirhinal and parahippocampal cortices of the macaque monkey: cortical afferents. J Comp Neur 350:497-533. CrossRef Medline

Toner CK, Pirogovsky E, Kirwan CB, Gilbert PE (2009) Visual object pattern separation deficits in nondemented older adults. Learn Mem 16:338-342. CrossRef Medline

Treves A, Rolls ET (1994) Computational analysis of the role of the hippocampus in memory. Hippocampus 4:374-391. CrossRef Medline

Warburton EC, Baird AL, Morgan A, Muir JL, Aggleton JP (2000) Disconnecting hippocampal projections to the anterior thalamus produces deficits on tests of spatial memory in rats. Eur $\mathrm{J}$ Neurosci 12:1714-1726. Medline

Waung MW, Pfeiffer BE, Nosyreva ED, Ronesi JA, Huber KM (2008) Rapid translation of Arc/Arg3.1 selectively mediates mGluRdependent LTD through persistent increases in AMPAR endocytosis rate. Neuron 59:84-97. CrossRef Medline

Winters BD, Bussey TJ (2005a) Transient inactivation of perirhinal cortex disrupts encoding, retrieval, and consolidation of object recognition memory. J Neurosci 25:52-61.

Winters BD, Bussey TJ (2005b) Glutamate receptors in perirhinal cortex mediate encoding, retrieval, and consolidation of object recognition memory. J Neurosci 25:4243-4251.

Witter MP (2007) The perforant path: projections from the entorhinal cortex to the dentate gyrus. Prog Brain Res 163:43-61. CrossRef Medline

Yassa MA, Stark CE (2011) Pattern separation in the hippocampus. Trends Neurosci 34:515-525. CrossRef Medline

Ying SW, Futter M, Rosenblum K, Webber MJ, Hunt SP, Bliss TV, Bramham CR (2002) Brain-derived neurotrophic factor induces long-term potentiation in intact adult hippocampus: requirement for ERK activation coupled to CREB and upregulation of Arc synthesis. J Neurosci 22:1532-1540. Medline

Ziakopoulos Z, Tillett CW, Brown MW, Bashir ZI (1999) Input-and layer-dependent synaptic plasticity in the rat perirhinal cortex in vitro. Neuroscience 92:459-472. Medline 